\title{
Free Energies of Hydration for Metal Ions from Heats of Vaporization
}

\section{Kepp, Kasper Planeta}

Published in:

Journal of Physical Chemistry Part A: Molecules, Spectroscopy, Kinetics, Environment and General Theory

Link to article, DOI:

10.1021/acs.jpca.9b05140

Publication date:

2019

Document Version

Peer reviewed version

Link back to DTU Orbit

Citation (APA):

Kepp, K. P. (2019). Free Energies of Hydration for Metal Ions from Heats of Vaporization. Journal of Physical Chemistry Part A: Molecules, Spectroscopy, Kinetics, Environment and General Theory, 123(30), 6536-6546. https://doi.org/10.1021/acs.jpca.9b05140

\section{General rights}

Copyright and moral rights for the publications made accessible in the public portal are retained by the authors and/or other copyright owners and it is a condition of accessing publications that users recognise and abide by the legal requirements associated with these rights.

- Users may download and print one copy of any publication from the public portal for the purpose of private study or research.

- You may not further distribute the material or use it for any profit-making activity or commercial gain

- You may freely distribute the URL identifying the publication in the public portal

If you believe that this document breaches copyright please contact us providing details, and we will remove access to the work immediately and investigate your claim 


\section{A: Spectroscopy, Molecular Structure, and Quantum Chemistry}

Subscriber access provided by DTU Library

\section{Free Energies of Hydration for Metal Ions from Heats of Vaporization Kasper P. Kepp \\ J. Phys. Chem. A, Just Accepted Manuscript • DOI: 10.1021/acs.jpca.9b05140 • Publication Date (Web): 03 Jul 2019 \\ Downloaded from http://pubs.acs.org on July 8, 2019}

\section{Just Accepted}

"Just Accepted" manuscripts have been peer-reviewed and accepted for publication. They are posted online prior to technical editing, formatting for publication and author proofing. The American Chemical Society provides "Just Accepted" as a service to the research community to expedite the dissemination of scientific material as soon as possible after acceptance. "Just Accepted" manuscripts appear in full in PDF format accompanied by an HTML abstract. "Just Accepted" manuscripts have been fully peer reviewed, but should not be considered the official version of record. They are citable by the Digital Object Identifier (DOI®). "Just Accepted" is an optional service offered to authors. Therefore, the "Just Accepted" Web site may not include all articles that will be published in the journal. After a manuscript is technically edited and formatted, it will be removed from the "Just Accepted" Web site and published as an ASAP article. Note that technical editing may introduce minor changes to the manuscript text and/or graphics which could affect content, and all legal disclaimers and ethical guidelines that apply to the journal pertain. ACS cannot be held responsible for errors or consequences arising from the use of information contained in these "Just Accepted" manuscripts. 


\title{
Free Energies of Hydration for Metal Ions from Heats of Vaporization
}

\author{
Kasper P. Kepp* \\ Technical University of Denmark, DTU Chemistry, Building 206, 2800 Kgs. Lyngby, DK - Denmark. \\ *Phone: +045 452524 09. E-mail: kpj@kemi.dtu.dk
}

\begin{abstract}
Consistent thermochemical data are of major importance for predicting and rationalizing stability and reactivity throughout chemistry. The free energy of hydration $\left(\Delta \mathrm{G}_{\mathrm{hyd}}\right)$ substantially defines the aqueous chemistry of metal ions and aids our understanding of the properties of water and has thus been widely studied both theoretically and experimentally. This paper first shows that the experimental standard half reduction potential for the process $\mathrm{M}^{\mathrm{n}+}+\mathrm{n}^{-} \rightarrow \mathrm{M}$ is accurately described using a simplified version of Trasatti's thermochemical cycle involving the ionization potentials, $\Delta \mathrm{G}_{\text {hyd }}$ of $\mathrm{M}^{\mathrm{n}+}$, and the standard heat of vaporization $\left(\Delta \mathrm{H}_{\mathrm{vap}}\right)$ of $\mathrm{M}$. This approximation, which neglects entropy, is shown to be valid both by actual performance (uncertainty $\sim 0.1 \mathrm{~V}, \mathrm{R}^{2} \sim 0.99-1.00$ for available data for $\mathrm{M}^{3+}$ and $\mathrm{M}^{2+}$ ions) and by application of Trouton's rule for entropies of vaporization. Second, application of the formula allows the identification of many $\Delta \mathrm{G}_{\text {hyd }}$ values not reported before. Together with previously determined values, the compiled lists of $\Delta \mathrm{G}_{\mathrm{hyd}}$ are the most complete so far reported and are all thermochemically consistent, i.e. they agree with their corresponding thermochemical cycles. The numbers use the convention $\Delta \mathrm{G}_{\mathrm{hyd}}\left(\mathrm{H}^{+}\right)=-1100 \mathrm{~kJ} / \mathrm{mol}$ and $\mathrm{SHE}=+4.44 \mathrm{~V}$, but can be easily adjusted to other reference states as appropriate. Some of the new $\Delta \mathrm{G}_{\text {hyd }}$ values established here are for the catalytically important dtransition metal ions $\mathrm{Rh}^{3+}, \mathrm{Re}^{3+}, \mathrm{Ir}^{3+}, \mathrm{Mo}^{3+}, \mathrm{W}^{3+}, \mathrm{Ge}^{2+}, \mathrm{Tc}^{2+}, \mathrm{Nb}^{3+}, \mathrm{Ta}^{3+}, \mathrm{Os}^{3+}$, and $\mathrm{Ru}^{2+}$. Some, such as $\mathrm{Ir}^{3+}$, are among the most inert aqua ions known. The $\Delta \mathrm{G}_{\text {hyd }}$ values have an accuracy of $\sim 10 \mathrm{~kJ} / \mathrm{mol}$ and are recommended for use in thermochemical calculations, for interpretation of the aqueous chemistry of the metal ions, and as benchmarks for theoretical chemistry.
\end{abstract}




\section{Introduction}

The behavior of metal ions $\left(\mathrm{M}^{\mathrm{n}+}\right)$ in water is of central importance to a wide range of processes in biology and chemistry and tells us much about the unique properties of water as a solvent. ${ }^{1-6}$ Specifically, the hydration free energy $\Delta \mathrm{G}_{\mathrm{hyd}}\left(\mathrm{M}^{\mathrm{n}+}\right)$ greatly contributes to the chemistry of the metal ion in aqueous solution and determines the ability of a metal ion to associate with or dissociate from water e.g. during transport through membranes or binding to host molecules. ${ }^{3,7-9}$ The relative magnitude of $\Delta \mathrm{G}_{\mathrm{hyd}}\left(\mathrm{M}^{\mathrm{n}+}\right)$ determines much of the selectivity of different ions toward host molecules such as proteins, membranes, and other macromolecules and materials. ${ }^{10-13}$ The $\Delta \mathrm{G}_{\mathrm{hyd}}\left(\mathrm{M}^{\mathrm{n}+}\right)$ is also important for understanding the redox chemistry and stability of ions in solution, as $\Delta \mathrm{G}_{\mathrm{hyd}}\left(\mathrm{M}^{\mathrm{n}+}\right)$ directly relates the vacuum ionization potential to the standard reduction potential of M. ${ }^{14-18}$

Values of $\Delta \mathrm{G}_{\mathrm{hyd}}\left(\mathrm{M}^{\mathrm{n}+}\right)$ derived from experiment constitute important benchmark data for understanding these phenomena and for the evaluation of theoretical methods such as semi-classical water models, density functional theory (DFT), and classical force fields. ${ }^{19-26}$ The simulated properties of an ion in water studied by molecular dynamics depends critically on the $\Delta \mathrm{G}_{\mathrm{hyd}}\left(\mathrm{M}^{\mathrm{n}+}\right)$ that the applied force field produces, as any error in this value biases the tendency of the ion to stick within its current hydration shell, and these energies should be put on scale with corresponding anions to avoid artefacts in water's preferential association with the ions. ${ }^{27,28}$ When simulating ion-host systems such as channels and ion pumps one should use classical force fields that adequately describe $\Delta \mathrm{G}_{\mathrm{hyd}}\left(\mathrm{M}^{\mathrm{n}+}\right)$ by explicit parameterization to experimental values, to enable an accurate description of the energetics of moving the ion from water to the host.

Many values of $\Delta \mathrm{G}_{\mathrm{hyd}}\left(\mathrm{M}^{\mathrm{n}+}\right)$ have been tabulated by e.g. Noyes ${ }^{29}$, Rosseinsky ${ }^{30}$, Fawcett ${ }^{31}$, Rizkalla and Choppin ${ }^{32}$, and Latimer ${ }^{16,17}$, and in particular by Marcus ${ }^{8,33,34}$. It is important to create a consensus among these values. It is also important to ensure that these values are "thermochemically consistent", i.e. that they are consistent with other data when applied in thermochemical cycles. ${ }^{35}$ Following the work of Trasatti, one can calculate $\Delta \mathrm{G}_{\mathrm{hyd}}\left(\mathrm{M}^{\mathrm{n}+}\right)$ from thermochemical cycles involving the standard half potentials $\mathrm{E}_{\frac{1}{2}}{ }^{0}$ and ionization potentials (IP). ${ }^{14,36,37}$ Emphasis should be on adhering to acceptable standard states ( $298.15 \mathrm{~K}$; unity activity; 1 atm partial pressure) and consensus reference values of $\Delta \mathrm{G}_{\mathrm{hyd}}\left(\mathrm{H}^{+}\right)=-1100 \pm 3 \mathrm{~kJ} / \mathrm{mol}^{18,39}$ and the standard hydrogen electrode (SHE), $\mathrm{E}^{0}{ }_{\mathrm{SHE}}(\mathrm{abs})=$ $+4.44 \mathrm{~V} \pm 0.02 \mathrm{~V}^{37}$.

Using this principle, new consistent $\Delta \mathrm{G}_{\mathrm{hyd}}\left(\mathrm{M}^{\mathrm{n}+}\right)$ values for all divalent and trivalent metal ions $\mathrm{M}^{2+}$ and $\mathrm{M}^{3+}$ were recently calculated by using the gas phase ionization potentials, which are available at very high accuracy, and the many tabulated values of standard reduction potentials. ${ }^{35}$ Since these data 
rely on those of Marcus in at least one of the oxidation states they also rely on the tetraphenylarsonium tetraphenylborate (TATB) extra-thermodynamic assumption for separating anion and cation hydration ${ }^{40}$ and carry the same potential flaws ${ }^{41,42}$; however comparison to available data once corrected for reference states indicates errors of the order of $\sim 10 \mathrm{~kJ} / \mathrm{mol}$, which is close to the limit of accuracy achievable for the absolute potentials. ${ }^{35,37}$ This protocol requires a thermochemical cycle of $\mathrm{M}^{3+}$ and $\mathrm{M}^{2+}$ ions together, thus obscuring values for many important metal ions. For example, the free energy of hydration of catalytically important ions such as $\mathrm{Rh}^{3+}, \mathrm{Re}^{3+}, \mathrm{Ir}^{3+}, \mathrm{W}^{3+}$, and $\mathrm{Ru}^{2+}$ are not tabulated in the references mentioned above and would be valuable assets to the thermochemically consistent scale.

In the present paper, it is shown that values of $\Delta \mathrm{G}_{\mathrm{hyd}}\left(\mathrm{M}^{\mathrm{n}+}\right)$ can be obtained from a thermochemical cycle using the heat of vaporization as a proxy of the atomization free energy of the metal, as the introduced entropy error is small. Since many values of heats of vaporization are known at good accuracy for metals ${ }^{43}$, this enables the computation of several new $\Delta \mathrm{G}_{\text {hyd }}\left(\mathrm{M}^{2+}\right)$ and $\Delta \mathrm{G}_{\text {hyd }}\left(\mathrm{M}^{3+}\right)$ values. Since these values are derived from experimental data only, they have the same accuracy as the involved experiments, or as shown here having a numerical accuracy of $\sim 10 \mathrm{~kJ} / \mathrm{mol}$ and a trend accuracy of $\mathrm{R}^{2}=0.99-1.00$. New $\Delta \mathrm{G}_{\text {hyd }}$ values are established for important d-transition metal ions $\mathrm{Rh}^{3+}, \mathrm{Re}^{3+}$, $\mathrm{Ir}^{3+}, \mathrm{Mo}^{3+}, \mathrm{W}^{3+}, \mathrm{Ge}^{2+}, \mathrm{Tc}^{2+}, \mathrm{Nb}^{3+}, \mathrm{Ta}^{3+}, \mathrm{Os}^{3+}$, and $\mathrm{Ru}^{2+}$. 


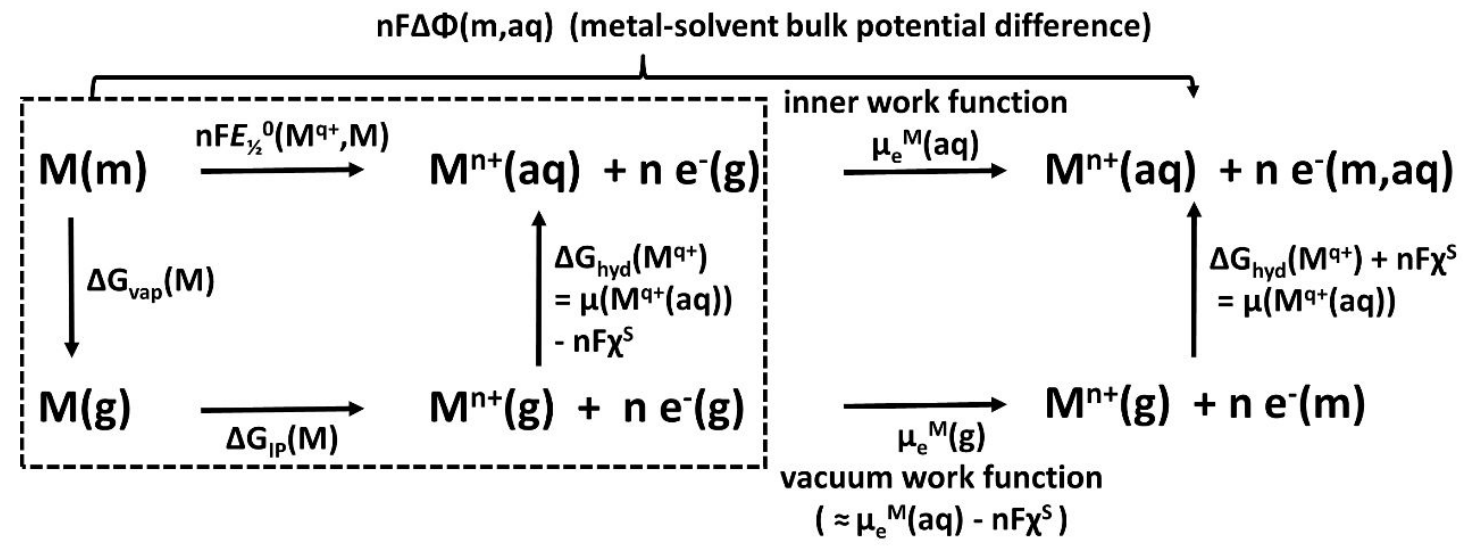

Figure 1. Thermochemical cycle used to calculate standard half reduction potential of the metal M. The dashed rectangle describes the cycle approximated in this work, whereas the remaining steps to the right represent important processes from a measuring perspective, which include the work functions of the metal M; (m), (g), and (aq) refer to the pure metal, gas, and aqueous states, respectively. Please see text for further details.

\section{Methods}

Conventions used. The values reported in this paper refer to the standard states applied in the experimental data from which they were derived, i.e. unity activities ( $\sim 1 \mathrm{M}$ concentrations), $\mathrm{T}=298.15$ $\mathrm{K}$, and $1 \mathrm{~atm}$ pressure. The values are reported relative to the value of the hydration free energy of the proton, $\Delta \mathrm{G}_{\text {hyd }}\left(\mathrm{H}^{+}\right)$. In previous work ${ }^{35}$ as well as here, we use the modern consensus of $\Delta \mathrm{G}_{\text {hyd }}\left(\mathrm{H}^{+}\right)=$$1100 \pm 5 \mathrm{~kJ} / \mathrm{mol}$, based mainly on the values by Zhan and Dixon $(-1098 \mathrm{~kJ} / \mathrm{mol})^{44}$ and Tissandier et al. $(-1104.5 \mathrm{~kJ} / \mathrm{mol}){ }^{38} \Delta \mathrm{G}_{\mathrm{hyd}}\left(\mathrm{H}^{+}\right)$differs from the chemical potential of the proton in water, $\mu\left(\mathrm{H}^{+}\right)(\mathrm{aq})$ by the value of the surface potential of water, $\chi^{\mathrm{S}}$ as described by Equation (1):37,45

$$
\Delta \mathrm{G}_{\mathrm{hyd}}\left(\mathrm{H}^{+}\right)=\mu\left(\mathrm{H}^{+}\right)(\mathrm{aq})-\mathrm{F} \chi^{\mathrm{S}}
$$

where F is Faraday's constant converting from potential to energy. The standard chemical potential of the proton was calculated by Trasatti $^{37}$ and Farrell and McTigue ${ }^{46}$ to be $-1088 \mathrm{~kJ} / \mathrm{mol}$. Fawcett ${ }^{45}$ obtained this value from the work function of mercury and another value of $-1091 \mathrm{~kJ} / \mathrm{mol}$ by analyzing the data reported by Randles ${ }^{47}$. This gives an estimate of the accuracy of this number of $\pm 3 \mathrm{~kJ} / \mathrm{mol}$. From the difference according to Equation (1) the surface potential $\chi^{\mathrm{S}}$ was estimated by Trasatti to be $+0.13 \mathrm{~V}^{37}$, by Farrell and McTigue to be $+0.025 \mathrm{~V}^{46}$, and by Krishtalik to be $+0.14 \mathrm{~V}^{48}$. In addition, Parfenyuk has estimated a consensus value of $+0.10 \mathrm{~V}$ from a survey of data ${ }^{49}$. Thus, $\chi^{\mathrm{S}}$ has an accuracy of $\pm 0.05 \mathrm{~V}(5 \mathrm{~kJ} / \mathrm{mol})$. These points were discussed by Farrell and McTigue, who computed the numbers 
as $+4.31 \mathrm{~V}$ and $+4.44 \mathrm{~V}^{46}$; the latter is the value of SHE used here. Considering the experimental measurement uncertainties of perhaps $\sim 5 \mathrm{~kJ} / \mathrm{mol}$, the values of $\Delta \mathrm{G}_{\mathrm{hyd}}\left(\mathrm{M}^{\mathrm{n}+}\right)$ reported in this work has an estimated uncertainty of $\pm 10 \mathrm{~kJ} / \mathrm{mol}$ as confirmed by explicit calculation below. The uncertainty is probably slightly larger for the trivalent ions, since we can expect that the errors scale monotonously with the magnitude of $\Delta \mathrm{G}_{\text {hyd }}$.

Thermochemical cycle and heat approximation. The thermochemical cycle used in this work is shown in Figure 1 and follows closely the work by Trasatti. ${ }^{37}$ The work functions corresponding to the bulk and vacuum situations are included for completeness but not used in this work (the work function is included in the metal-solvent bulk potential difference, written $\Delta \Phi$ in Figure 1). For the purpose of the present work, the standard half reduction potential $E_{1 / 2} 0\left(\mathrm{M}^{\mathrm{n}+} / \mathrm{M}\right)$ for a metal M,

$$
\mathrm{M}^{\mathrm{n}+}+n \mathrm{e}^{-} \rightarrow \mathrm{M}
$$

can be computed from a Born-Haber cycle ${ }^{37}$ :

$$
E_{1 / 2}^{0}\left(\mathrm{M}^{\mathrm{n}+} / \mathrm{M}\right)=\left(\Delta \mathrm{G}_{\mathrm{at}}{ }^{0}+\Delta \mathrm{G}_{\mathrm{IP}}(\mathrm{M})+\Delta \mathrm{G}_{\mathrm{hyd}}\left(\mathrm{M}^{\mathrm{n}+}\right)\right) / n \mathrm{~F}-\mathrm{SHE}
$$

which is reflected by the dashed rectangle in Figure 1. Please note that as the free energies are summed as indicated by the arrows in this rectangle in Figure 1. This corresponds to the free energy of the oxidation process of $\mathrm{M}$, which is the negative of the reduction process; to convert to potential one more sign inversion takes place such that the computed potentials in Equation (3) are standard reduction potentials, explaining the positive value of $n F E_{1 / 2}^{0}\left(\mathrm{M}^{\mathrm{n}+} / \mathrm{M}\right)$ in Figure 1.

In Equation (3), $\Delta \mathrm{G}_{\mathrm{at}}{ }^{0}$ is the standard atomization free energy of the metal, which can be approximated as the free energy of vaporization $\Delta \mathrm{G}_{\mathrm{vap}}(\mathrm{M})$ as in Figure 1, because the enthalpy of fusion is small and similar (around 10-20 kJ/mol) for the metals and cancels with the entropy terms as shown below. $\Delta \mathrm{G}_{\mathrm{IP}}(\mathrm{M})$ is the sum of ionization free energies that convert $\mathrm{M}$ to $\mathrm{M}^{\mathrm{n}+}$; thus, e.g. if $n=2$, the value represents the sum of the first and second ionization free energies of M. Equation (3) includes a correction to the relative scale of the desired reference electrode, in this case SHE $=+4.44 \mathrm{~V}$, which includes the surface potential $\chi^{\mathrm{S}}$. This corresponds to the cycle by Trasatti, because he uses $\mu\left(\mathrm{H}^{+}\right)(\mathrm{aq})$ from Equation (1) and $\mathrm{SHE}=+4.31 \mathrm{~V}$, i.e. without $\chi^{\mathrm{S}}$, which cancels out in Equation (3). One can convert between the thermochemical and operational electrode potentials by using $+4.31 \mathrm{~V}$ instead of $+4.44 \mathrm{~V}$, to make the tabulated $\Delta \mathrm{G}_{\text {hyd }}$ values $13 \mathrm{~kJ} / \mathrm{mol}$ smaller. Other choices can be made for $\Delta \mathrm{G}_{\text {hyd }}\left(\mathrm{H}^{+}\right)$ and can easily be used to calculate revised $\Delta \mathrm{G}_{\text {hyd }}$ from the data presented here. Notably, if the interest is in conventional free energies of hydration $\left(\Delta \mathrm{G}_{\mathrm{hyd}}\left(\mathrm{H}^{+}\right)=0\right)$, the value $-1100 n \mathrm{~kJ} / \mathrm{mol}$ should be subtracted 
from the tabulated data. In computational chemistry, $\mu\left(\mathrm{M}^{\mathrm{n}+}\right)(\mathrm{aq})$ is typically estimated rather than $\Delta \mathrm{G}_{\text {hyd }}\left(\mathrm{M}^{\mathrm{n}+}\right)$ due to the absence of a surface potential effect, and thus $\mathrm{SHE}=+4.31 \mathrm{~V}$ should be used.

Many values of $E_{1 / 2}{ }^{0}\left(\mathrm{M}^{\mathrm{n}+} / \mathrm{M}\right)$ and $\Delta \mathrm{G}_{\mathrm{hyd}}\left(\mathrm{M}^{\mathrm{n}+}\right)$ are known, but even more ionization potentials are available at very high accuracy in the NIST database. Errors arising from the cycle are mainly due to the errors in $\Delta \mathrm{G}_{\mathrm{at}}{ }^{0}$, and $\Delta \mathrm{G}_{\mathrm{hyd}}\left(\mathrm{M}^{\mathrm{n}+}\right)$. For $\Delta \mathrm{G}\left(\mathrm{IP}_{\mathrm{n}}, \mathrm{M}\right)$ the only error is caused by the entropy of ionization that converts the ionization energies into free energies. This entropy amounts to a few $\mathrm{kJ} / \mathrm{mol}$ at $298 \mathrm{~K}$ and can thus be neglected. ${ }^{37}$ A second error relates to the estimation of $\Delta \mathrm{G}_{\mathrm{at}}{ }^{0}$, as these data are not generally available. However, the enthalpies of vaporization, $\Delta \mathrm{H}_{\mathrm{vap}}$ are widely known and tabulated. ${ }^{43}$ They are shown below to be an excellent proxy of $\Delta \mathrm{G}_{\mathrm{at}}{ }^{0}$, mainly due to the small enthalpies of fusion that cancel with the entropy of fusion and the entropy of vaporizing the metal $\left(\Delta \mathrm{S}_{\mathrm{vap}}\right)$, which is also small and very similar for most metals; this fact is commonly referred to as Trouton's rule. ${ }^{50}$ These cancellations are very useful as shown below. Inclusion or neglect of the Trouton entropy $\left(\Delta \mathrm{S}_{\mathrm{vap}}=10.5 \mathrm{R}\right.$ corresponding to $\mathrm{T} \Delta \mathrm{S}_{\mathrm{vap}}=0.27 / n \mathrm{~V}$ at $298 \mathrm{~K}$ ) gives similar small mean signed errors but of opposite signs, quantifying the cancellation of error. Because of these various cancellations, Equation (4),

$$
E_{1 / 2}^{0}\left(\mathrm{M}^{\mathrm{n}+} / \mathrm{M}\right)=\left(\Delta \mathrm{H}_{\mathrm{vap}}+\mathrm{IP}_{\mathrm{n}}(\mathrm{M})+\Delta \mathrm{G}_{\mathrm{hyd}}\left(\mathrm{M}^{\mathrm{n}+}\right)\right) / n \mathrm{~F}-4.44 \mathrm{~V}
$$

applies with errors averaging to only $10 \mathrm{~kJ} / \mathrm{mol}(0.1 \mathrm{~V})$ as shown by explicit application below. From this useful equation, any missing quantity can be calculated if the remaining quantities are available. In this work, we show first the validity of Equation (4) and then use it to derive values of $\Delta \mathrm{G}_{\mathrm{hyd}}\left(\mathrm{M}^{\mathrm{n}+}\right)$ that have not previously been reported in the literature, and to correct some values that have been reported.

Data used. Values of $\mathrm{E}_{1 / 2}^{0}$ were taken from the CRC Handbook ${ }^{51}$ and from Bratsch. ${ }^{52}$ Data can be found in Supporting Information, Table S1 for $\mathrm{M}^{3+}$ ions and Table S2 for $\mathrm{M}^{2+}$ ions. The values for $\Delta \mathrm{H}_{\text {vap }}$ were taken as reported in the Chemistry Data Book ${ }^{53}$ and validated by Zhang et al. ${ }^{43}$ The $\Delta \mathrm{G}_{\text {hyd }}$ used for testing the approximation of Equation (4) were the recently derived values ${ }^{35}$ that are thermochemically consistent, i.e. the values for each metal agree with their thermochemical cycles.

The experimental data may in some cases relate to a mixture of species or a species that differs from other hydrated species although all of them are referred to as " $\mathrm{M}^{\mathrm{n}+}(\mathrm{aq})$ ". All data in this work accordingly also refers to the real species or mixtures. A notable example is the deprotonation of a water of the first coordination shell of the $\mathrm{M}^{3+}$ ions caused by the Brønsted acidity of these aqua complexes, and the hydrolytic instability and possibly mixed nature of some species such as $\mathrm{Co}^{3+}(\mathrm{aq}) .{ }^{54}$ Since all data reported here are based on the active species in solution that give rise to the observed values, this does not affect the accuracy of the tabulated data. However, variations in chemical composition and coordination number will potentially weaken the trend chemistry ${ }^{55}$ as discussed further below. In 
addition, the fact that data refer to the real species during measurement, not necessarily a single species, should be considered when estimating these values by computational chemistry.

\section{Results and Discussion}

Test of the validity of the applied approximation. The approximation of using $\Delta \mathrm{H}_{\mathrm{vap}}$ as in Equation (4) can be directly tested by applying Equation (4) to cases of $M$ where all values in Equation (4) are known. Figure 2 shows this relationship for all the $\mathrm{M}^{3+}$ and $\mathrm{M}^{2+}$ ions for which data were found. The cycle-consistent values of $\Delta \mathrm{G}_{\text {hyd }}\left(\mathrm{M}^{\mathrm{n}+}\right)$ were used ${ }^{35}$. It should be noted that the choice of reference SHE and $\Delta \mathrm{G}_{\text {hyd }}\left(\mathrm{H}^{+}\right)$will not affect the trend agreement $\left(R^{2}\right)$ in Figure 2. The accuracy of the approximated cycle emerges from the standard error of the linear regression. The test includes $28 \mathrm{M}^{3+}$ ions and $33 \mathrm{M}^{2+}$ ions. The data can be found in Supporting Information, Table S3 and Table S4.

To understand the impact of the entropy of vaporization on the quality of the approximation, the linear regression was performed both with and without application of Trouton's rule. ${ }^{50}$ When included, a value of $10.5 \mathrm{R}$, corresponding to $0.27 / n \mathrm{~V}$ at $298.15 \mathrm{~K}$ (the Trouton entropy of vaporization measured as a potential) was subtracted from the calculated $E_{1 / 2} 0\left(\mathrm{M}^{\mathrm{n}+} / \mathrm{M}\right)$ of Equation (4). Figure $2 \mathrm{~A}$ shows the relation between experimental values of $E_{\frac{1}{2}}{ }^{0}\left(\mathrm{M}^{2+} / \mathrm{M}\right)$ (in V) and those calculated from Equation (4) for the $\mathrm{M}^{2+}$ ions if the $\Delta \mathrm{H}_{\mathrm{vap}}$ is not included. For comparison, Figure 2B shows the same relation when $\Delta \mathrm{H}_{\text {vap }}$ is included, using Equation (4) in full. Figure 2C uses Equation (4) completely as in Figure 2B but includes the Trouton entropy correction. Figure 2D-2F show the same relationships for the $\mathrm{M}^{3+}$ ions.

As seen from Figure 2, regardless of the metal oxidation state, Equation (4) adequately describes the experimental standard reduction potentials. The use of the enthalpies of vaporization improves the trend agreement from $\mathrm{R}^{2}=0.83$ for $\mathrm{M}^{2+}$ ions and 0.94 for $\mathrm{M}^{3+}$ ions when the term is disregarded (Figure 2A, 2C) to $\mathrm{R}^{2}=0.99-1.00$ when included (Figure 2B, 2D). For the $\mathrm{M}^{2+}$ ions, the mean absolute error (MAE) without considering $\Delta \mathrm{G}_{\mathrm{at}}{ }^{0} / \Delta \mathrm{H}_{\mathrm{vap}}$ is $1.24 \mathrm{~V}$, with a mean signed error (MSE) of $-1.24 \mathrm{~V}$. For the $\mathrm{M}^{3+}$ ions, the MAE is $0.98 \mathrm{~V}$ and MSE is $-0.98 \mathrm{~V}$. Accordingly, for both oxidation states the neglect of the atomization free energy produces too small reduction potentials of $\sim 1 \mathrm{~V}$, because this free energy is always positive and dominated by $\Delta \mathrm{H}_{\mathrm{vap}}$, as it reflects the breaking of the metal-metal bonds. The Trouton entropy compensates this somewhat by favoring release of the metal atoms to the gas state. Complete neglect of $\Delta \mathrm{G}_{\mathrm{at}}{ }^{0}$ thus favors reaction towards the right in Figure 1, away from the reduced metal state. In an electrochemical measurement, the energy required to release the metal atoms from the bulk metal during the oxidation process is thus a major contributor to the observed potentials. 


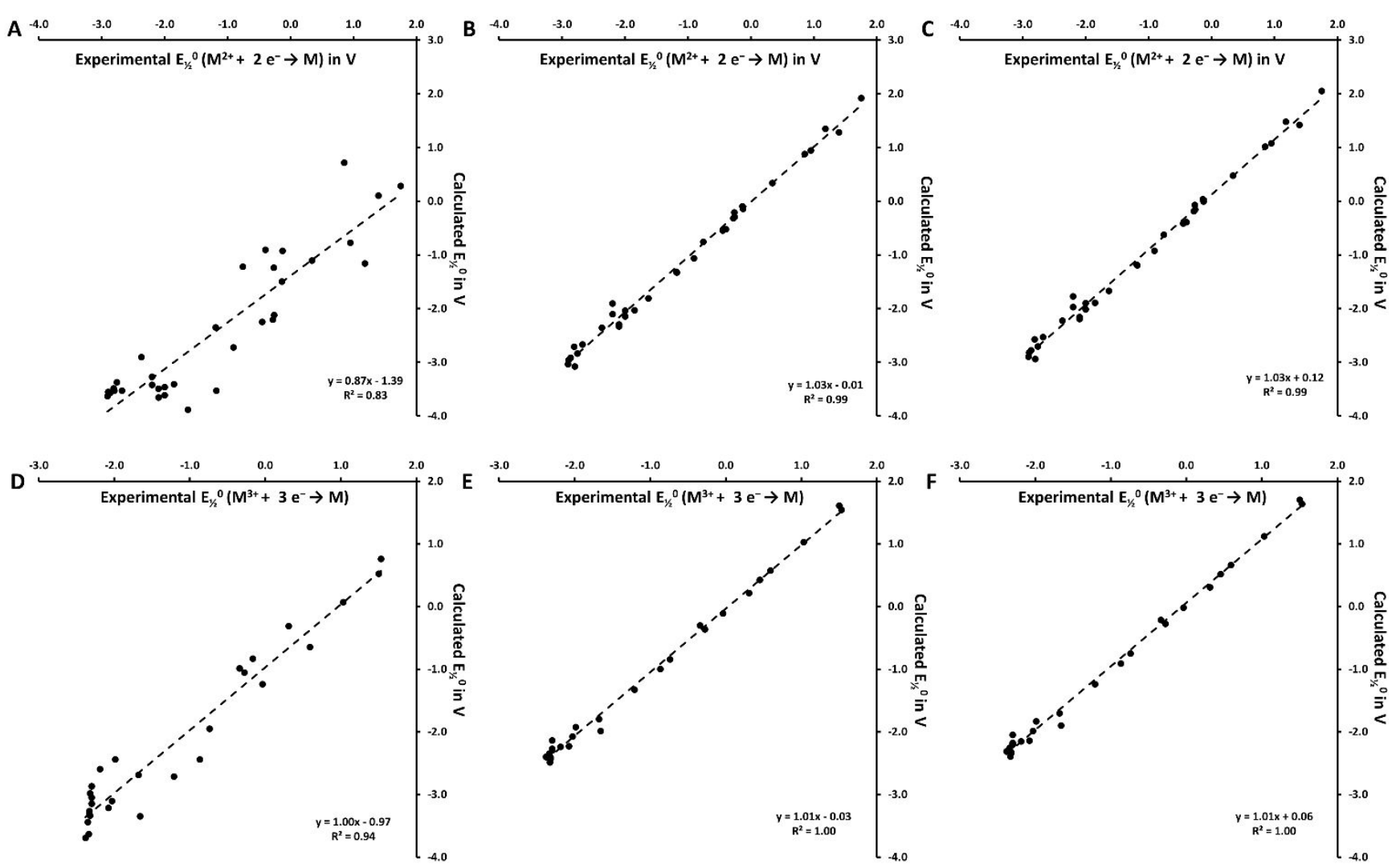

Figure 2. A) Relation between $E_{1 / 2}^{0}$ (in $V$ ) and $E_{1 / 2}^{0}$ calculated from the IPs and $\Delta \mathrm{G}_{\mathrm{hyd}}$ for $\mathrm{M}^{2+}$ ions. B) Relation using a thermochemical cycle that includes $\Delta \mathrm{H}_{\mathrm{vap}}$. C) Same as B) but included an entropy correction based on Trouton's rule. D) Same as A) for $\mathrm{M}^{3+}$ ions. E) Same as B) for $\mathrm{M}^{3+}$ ions. F) Same as C) for $\mathrm{M}^{3+}$ ions. All values used are experimental (directly or derived by thermochemical cycles).

When one includes $\Delta \mathrm{H}_{\text {vap }}$ and uses Equation (4) specifically (Figure 2B, 2D), MES = -0.04 V and $\mathrm{MAE}=0.10 \mathrm{~V}$ for $\mathrm{M}^{2+}$ ions, and $\mathrm{MSE}=-0.05 \mathrm{~V}$ and $\mathrm{MAE}=0.08 \mathrm{~V}$ for the $\mathrm{M}^{3+}$ ions. Because the systematic error is of the order of chemical accuracy, the approximation of using Equation (4) directly is adequate. The reason largely relates to the fact that $\Delta \mathrm{S}_{\mathrm{vap}}{ }^{0}$ is similar for all metals, consistent with Trouton's rule ${ }^{50}$. To see this, inclusion of the Trouton entropy in Figure 2C and 2F does not change trend agreement and does not improve numerical accuracy $\left(\mathrm{MAE}=0.12 \mathrm{~V}\right.$ and $0.08 \mathrm{~V}$ for $\mathrm{M}^{2+}$ and $\mathrm{M}^{3+}$ ions, respectively, Table S3 and Table S4). Because $\Delta \mathrm{S}_{\mathrm{vap}}{ }^{0}$ reduces slightly the positive free energy of vaporization, the signed error becomes of similar magnitude but with opposite sign (0.04-0.10 V). The remaining error arises from the gas phase ionization entropy of a few $\mathrm{kJ} / \mathrm{mol}$ at $298 \mathrm{~K}$, as discussed by Trasatti $^{37}$. Considering the experimental measurement uncertainty and the uncertainty in the choice of reference $\Delta \mathrm{G}_{\mathrm{hyd}}\left(\mathrm{H}^{+}\right)$, this minor correction does not affect the accuracy of the absolute potentials, and fully cancels out in the trend chemistry (i.e. relative potentials and relative free energies of hydration). 
Table 1. Free energies of hydration for $\mathrm{M}^{3+}$ ions $(\mathrm{kJ} / \mathrm{mol})$.

\begin{tabular}{|c|c|c|c|c|c|c|c|}
\hline & Marcus $^{33,34}$ & Marcus $^{8}$ & Noyes $^{29}$ & Fawcett $^{31, b}$ & $\begin{array}{l}\text { Rizkalla \& } \\
\text { Choppin }^{32}\end{array}$ & $\mathrm{Kepp}^{35}$ & This work \\
\hline $\mathrm{Ac}^{3+}$ & N/A & -3179 & N/A & N/A & N/A & N/A & -3086 \\
\hline $\mathrm{Ag}^{3+}$ & N/A & N/A & N/A & N/A & N/A & -4683 & \\
\hline $\mathrm{Al}^{3+}$ & -4525 & -4554 & N/A & -4662 & N/A & -4657 & \\
\hline $\mathrm{Au}^{3+}$ & -4420 & $\mathrm{~N} / \mathrm{A}$ & N/A & N/A & N/A & -4324 & \\
\hline $\mathrm{Bi}^{3+}$ & -3480 & -3508 & N/A & N/A & N/A & -3612 & \\
\hline $\mathrm{Ce}^{3+}$ & -3200 & N/A & N/A & N/A & -3240 & -3332 & \\
\hline $\mathrm{Co}^{3+}$ & -4495 & -4527 & N/A & $\mathrm{N} / \mathrm{A}$ & N/A & -4622 & \\
\hline $\mathrm{Cr}^{3+}$ & -4010 & -4517 & -4339 & -4531 & N/A & -4536 & \\
\hline $\mathrm{Cu}^{3+}$ & N/A & N/A & N/A & N/A & N/A & -4979 & \\
\hline $\mathrm{Dy}^{3+}$ & -3425 & -3457 & N/A & $\mathrm{N} / \mathrm{A}$ & -3481 & -3557 & \\
\hline $\mathrm{Er}^{3+}$ & -3495 & -3523 & N/A & N/A & -3537 & -3627 & \\
\hline $\mathrm{Eu}^{3+}$ & -3360 & -3395 & -3527 & N/A & -3397 & -3476 & \\
\hline $\mathrm{Fe}^{3+}$ & -4265 & -4296 & -4335 & -4416 & N/A & -4383 & \\
\hline $\mathrm{Ga}^{3+}$ & N/A & -4542 & N/A & -4670 & N/A & N/A & -4654 \\
\hline $\mathrm{Gd}^{3+}$ & N/A & -3411 & $\mathrm{~N} / \mathrm{A}$ & N/A & -3421 & N/A & $-3415 /-3500^{b}$ \\
\hline $\mathrm{Ho}^{3+}$ & -3470 & -3493 & N/A & N/A & -3510 & -3602 & \\
\hline $\mathrm{In}^{3+}$ & -3980 & -4012 & -4100 & -4121 & N/A & -4112 & \\
\hline $\mathrm{Ir}^{3+}$ & $\mathrm{N} / \mathrm{A}$ & N/A & N/A & $\mathrm{N} / \mathrm{A}$ & N/A & N/A & -4150 \\
\hline $\mathrm{La}^{3+}$ & -3145 & -3176 & N/A & N/A & -3193 & -3277 & \\
\hline $\mathrm{Lu}^{3+}$ & N/A & -3545 & N/A & $\mathrm{N} / \mathrm{A}$ & -3609 & N/A & -3698 \\
\hline $\mathrm{Mn}^{3+}$ & $\mathrm{N} / \mathrm{A}$ & N/A & $\mathrm{N} / \mathrm{A}$ & $\mathrm{N} / \mathrm{A}$ & N/A & -4520 & \\
\hline $\mathrm{Mo}^{3+}$ & N/A & N/A & N/A & N/A & N/A & N/A & -4250 \\
\hline $\mathrm{Nb}^{3+}$ & N/A & N/A & N/A & N/A & N/A & N/A & -4165 \\
\hline $\mathrm{Nd}^{3+}$ & -3280 & -3308 & N/A & N/A & -3311 & -3412 & \\
\hline $\mathrm{Ni}^{3+}$ & N/A & $\mathrm{N} / \mathrm{A}$ & N/A & N/A & N/A & -4813 & \\
\hline $\mathrm{Np}^{3+}$ & N/A & N/A & N/A & N/A & N/A & N/A & -3203 \\
\hline $\mathrm{Os}^{3+}$ & $\mathrm{N} / \mathrm{A}$ & N/A & N/A & N/A & N/A & N/A & -4000 \\
\hline $\mathrm{Pa}^{3+}$ & N/A & N/A & N/A & $\mathrm{N} / \mathrm{A}$ & N/A & $\mathrm{N} / \mathrm{A}$ & -3084 \\
\hline $\mathrm{Pm}^{3+}$ & -3250 & -3328 & N/A & N/A & -3341 & -3382 & $-3430^{c}$ \\
\hline $\mathrm{Pr}^{3+}$ & -3245 & -3273 & N/A & N/A & -3278 & -3377 & \\
\hline $\mathrm{Pu}^{3+}$ & -3235 & N/A & N/A & N/A & N/A & -3367 & \\
\hline $\mathrm{Re}^{3+}$ & N/A & N/A & N/A & N/A & N/A & N/A & -4298 \\
\hline $\mathrm{Rh}^{3+}$ & N/A & N/A & N/A & N/A & N/A & N/A & -4450 \\
\hline $\mathrm{Ru}^{3+}$ & N/A & N/A & N/A & N/A & N/A & N/A & $-4295^{d}$ \\
\hline $\mathrm{Sc}^{3+}$ & -3795 & -3824 & N/A & -3933 & N/A & -3927 & \\
\hline $\mathrm{Sm}^{3+}$ & -3325 & -3353 & N/A & N/A & -3370 & -3456 & \\
\hline $\mathrm{Ta}^{3+}$ & N/A & $\mathrm{N} / \mathrm{A}$ & N/A & N/A & N/A & N/A & -4162 \\
\hline $\mathrm{Tb}^{3+}$ & N/A & -3435 & N/A & N/A & -3450 & N/A & -3549 \\
\hline $\mathrm{Tc}^{3+}$ & N/A & N/A & N/A & N/A & N/A & N/A & $-4170^{\mathrm{e}}$ \\
\hline $\mathrm{Ti}^{3+}$ & -4015 & N/A & -4046 & N/A & N/A & -4147 & \\
\hline $\mathrm{Tl}^{3+}$ & N/A & -3996 & N/A & -4122 & N/A & N/A & -4102 \\
\hline $\mathrm{Tm}^{3+}$ & -3515 & -3545 & N/A & N/A & -3563 & -3647 & \\
\hline $\mathrm{U}^{3+}$ & -3205 & -3306 & N/A & N/A & N/A & -3337 & \\
\hline $\mathrm{V}^{3+}$ & -4220 & -4285 & N/A & N/A & N/A & -4338 & \\
\hline $\mathrm{W}^{3+}$ & N/A & N/A & N/A & N/A & N/A & N/A & -4306 \\
\hline $\mathrm{Y}^{3+}$ & $\mathrm{N} / \mathrm{A}$ & -3450 & N/A & $\mathrm{N} / \mathrm{A}$ & -3497 & N/A & -3523 \\
\hline $\mathrm{Yb}^{3+}$ & -3570 & -3494 & N/A & N/A & -3587 & -3688 & \\
\hline
\end{tabular}

${ }^{a}$ Values by Fawcett were converted from conventional data using $\Delta \mathrm{G}_{\mathrm{hyd}}\left(\mathrm{H}^{+}\right)=-1100 \mathrm{~kJ} / \mathrm{mol} .{ }^{\mathrm{b}}-3415 \mathrm{~kJ} / \mathrm{mol}$ from Equation (4) is too large as seen from the lanthanide trend, probably due to error in $\Delta \mathrm{H}_{\text {vap }} ;-3500 \mathrm{~kJ} / \mathrm{mol}$ is estimated from the trend. ${ }^{\mathrm{c}}$ The value previously reported ${ }^{35}$ was based on an older number by Marcus $(-3250 \mathrm{~kJ} / \mathrm{mol})$, converted to $\Delta \mathrm{G}_{\mathrm{hyd}}\left(\mathrm{H}^{+}\right)=-1100 \mathrm{~kJ} / \mathrm{mol}$. The new value is his 2015 value $(-3328$ $\mathrm{kJ} / \mathrm{mol}$ ) converted from $\Delta \mathrm{G}_{\mathrm{hyd}}\left(\mathrm{H}^{+}\right)=-1056$ to $-1100 \mathrm{~kJ} / \mathrm{mol}$, giving $-3430 \mathrm{~kJ} / \mathrm{mol}$ with good trend behavior. ${ }^{\mathrm{d}}$ Computed from $\mathrm{E}\left(\mathrm{Ru}^{3+} / \mathrm{Ru}^{2+}\right)$ $=+0.24 \mathrm{~V}^{52}$ and the value $-2000 \mathrm{~kJ} / \mathrm{mol}$ for $\mathrm{Ru}^{2+}$ found from Equation (4). ${ }^{\mathrm{e}}$ Same, using $\mathrm{E}\left(\mathrm{Tc}^{3+} / \mathrm{Tc}^{2+}\right)=+0.3 \mathrm{~V}$. 
Table 2. Free energies of hydration for $\mathrm{M}^{2+}$ ions $(\mathrm{kJ} / \mathrm{mol})$.

\begin{tabular}{|c|c|c|c|c|c|c|c|}
\hline & Marcus $^{33,34}$ & Marcus $^{8}$ & Noyes $^{29}$ & Fawcett $^{31, a}$ & $\begin{array}{l}\text { Rizkalla \& } \\
\text { Choppin }^{32}\end{array}$ & Kepp $^{35}$ & This work \\
\hline $\mathrm{Ag}^{2+}$ & -1865 & N/A & N/A & N/A & N/A & -1953 & \\
\hline $\mathrm{Au}^{2+}$ & N/A & N/A & N/A & N/A & N/A & -1954 & \\
\hline $\mathrm{Ba}^{2+}$ & -1250 & -1270 & -1314 & -1343 & N/A & -1338 & \\
\hline $\mathrm{Be}^{2+}$ & -2395 & -2417 & -2436 & -2489 & N/A & -2483 & \\
\hline $\mathrm{Ca}^{2+}$ & -1505 & -1527 & -1588 & -1599 & N/A & -1593 & \\
\hline $\mathrm{Cd}^{2+}$ & -1755 & -1748 & -1795 & -1820 & N/A & -1843 & \\
\hline $\mathrm{Co}^{2+}$ & -1915 & -1936 & -2013 & -2008 & N/A & -2003 & \\
\hline $\mathrm{Cr}^{2+}$ & -1850 & -1841 & -2013 & -1924 & N/A & -1938 & \\
\hline $\mathrm{Cu}^{2+}$ & -2010 & -2028 & -2076 & -2100 & N/A & -2086 & \\
\hline $\mathrm{Dy}^{2+}$ & N/A & N/A & N/A & N/A & -1463 & -1526 & \\
\hline $\mathrm{Er}^{2+}$ & N/A & N/A & N/A & N/A & -1495 & -1576 & \\
\hline $\mathrm{Eu}^{2+}$ & -1385 & -1409 & N/A & N/A & -1409 & -1473 & \\
\hline $\mathrm{Fe}^{2+}$ & -1840 & -1864 & -1890 & -1949 & N/A & -1928 & \\
\hline $\mathrm{Ge}^{2+}$ & N/A & N/A & N/A & N/A & N/A & N/A & -1726 \\
\hline $\mathrm{Hg}^{2+}$ & -1760 & -1778 & -1820 & -1850 & N/A & -1848 & \\
\hline $\mathrm{Ho}^{2+}$ & N/A & N/A & N/A & N/A & -1480 & -1561 & \\
\hline $\mathrm{In}^{2+}$ & N/A & N/A & N/A & N/A & N/A & -1787 & \\
\hline $\mathrm{Mg}^{2+}$ & -1830 & -1837 & -1900 & -1922 & N/A & -1918 & \\
\hline $\mathrm{Mn}^{2+}$ & -1760 & -1787 & -1826 & -1859 & N/A & -1848 & \\
\hline $\mathrm{Nd}^{2+}$ & N/A & N/A & N/A & N/A & -1360 & -1448 & \\
\hline $\mathrm{Ni}^{2+}$ & -1980 & -2014 & -2062 & -2087 & N/A & -2068 & \\
\hline $\mathrm{Pb}^{2+}$ & -1425 & -1510 & -1492 & -1518 & N/A & -1513 & \\
\hline $\mathrm{Pd}^{2+}$ & -1910 & -1957 & -2397 & N/A & N/A & -1998 & \\
\hline $\mathrm{Pm}^{2+}$ & N/A & N/A & N/A & N/A & -1378 & -1394 & \\
\hline $\mathrm{Po}^{2+}$ & N/A & N/A & N/A & N/A & N/A & N/A & -1848 \\
\hline $\mathrm{Pr}^{2+}$ & N/A & N/A & N/A & N/A & -1342 & -1420 & \\
\hline$\overline{\mathrm{Pt}^{2+}}$ & -1960 & -1969 & N/A & N/A & N/A & -2048 & \\
\hline $\mathrm{Pu}^{2+}$ & N/A & N/A & N/A & N/A & N/A & N/A & $-1489^{b}$ \\
\hline $\mathrm{Ra}^{2+}$ & -1250 & -1271 & -1280 & N/A & N/A & -1338 & \\
\hline $\mathrm{Ru}^{2+}$ & N/A & N/A & N/A & N/A & N/A & N/A & -2000 \\
\hline $\mathrm{Sc}^{2+}$ & N/A & N/A & N/A & N/A & N/A & N/A & $-1745^{c}$ \\
\hline $\mathrm{Sm}^{2+}$ & -1375 & -1388 & N/A & N/A & -1394 & -1463 & \\
\hline $\mathrm{Sn}^{2+}$ & -1490 & -1504 & -1554 & -1581 & N/A & -1578 & \\
\hline $\mathrm{Sr}^{2+}$ & -1380 & -1398 & -1421 & -1470 & N/A & -1468 & \\
\hline $\mathrm{Tc}^{2+}$ & N/A & N/A & N/A & N/A & N/A & N/A & -1776 \\
\hline $\mathrm{Ti}^{2+}$ & N/A & N/A & -1782 & N/A & N/A & -1887 & \\
\hline $\mathrm{Tm}^{2+}$ & N/A & N/A & N/A & N/A & -1509 & -1580 & \\
\hline $\mathrm{V}^{2+}$ & -1825 & -1602 & -1845 & N/A & N/A & -1913 & \\
\hline $\mathrm{Yb}^{2+}$ & -1510 & -1523 & N/A & N/A & -1523 & -1598 & \\
\hline $\mathrm{Zn}^{2+}$ & -1955 & -1975 & -2022 & -2048 & N/A & -2043 & \\
\hline
\end{tabular}

${ }^{a}$ Values reported by Fawcett were converted from conventional data using $\Delta \mathrm{G}_{\mathrm{hyd}}\left(\mathrm{H}^{+}\right)=-1100 \mathrm{~kJ} / \mathrm{mol}^{\mathrm{b}}{ }^{\mathrm{F}}$ From the value for Pu ${ }^{3+}(-3367)$ and $\mathrm{E}\left(\mathrm{Pu}^{3+/} \mathrm{Pu}^{2+}\right)=-2.80 \mathrm{~V} .{ }^{52} \mathrm{c}$ From the value for $\mathrm{Sc}^{3+}(-3927)$ and $\mathrm{E}\left(\mathrm{Sc}^{3+} \mathrm{Sc}^{2+}\right)=-2.30 \mathrm{~V} .{ }^{52}$ 
New free energies of hydration. Considering the accuracy of Equation (4), we can now apply it to deduce values of $\Delta \mathrm{G}_{\text {hyd }}$ for metal ions not reported previously in the literature, and we can also use the equation to test the thermochemical consistency (i.e. cycle-consistency) of previously reported values of $\Delta \mathrm{G}_{\text {hyd }}$. Table 1 and Table 2 show the new values of $\Delta \mathrm{G}_{\text {hyd }}$ compared with values of $\Delta \mathrm{G}_{\text {hyd }}$ values previously reported. For many of the data, the differences lie mainly in the choice of reference values for SHE and the hydration free energy of the proton, as discussed above. Thus, the relative values for two ions, in particular of the same oxidation state, are often similar for the new and old reported data, which is another illustration of the validity of Equation (4). These relative differences are chemically very important because they contribute substantially to the comparative chemistry, e.g. the selectivity of the ions towards host molecules in aqueous solution. ${ }^{11,12}$

Taking just one example, the difference in of $\Delta \mathrm{G}_{\text {hyd }}$ for $\mathrm{Ca}^{2+}$ and $\mathrm{Cd}^{2+}$, which is biologically important, is $250 \mathrm{~kJ} / \mathrm{mol}$ for the original data of Marcus ${ }^{34}$ and the cycle-consistent values previously calculated $^{35}$, but it is only $221 \mathrm{~kJ} / \mathrm{mol}$ when estimated from the data by Fawcett ${ }^{31}$ and the newer compilation by Marcus, ${ }^{8}$ and only $207 \mathrm{~kJ} / \mathrm{mol}$ using the data compiled by Noyes ${ }^{29}$, thus giving a spread in the relative $\Delta \mathrm{G}_{\text {hyd }}$ of $43 \mathrm{~kJ} / \mathrm{mol}$, which is clearly unacceptable. We do not know which values are correct. However, using the values that we reported previously $\left(-1593 \mathrm{~kJ} / \mathrm{mol}\right.$ for $\mathrm{Ca}^{2+} ;-1843 \mathrm{~kJ} / \mathrm{mol}$ for $\left.\mathrm{Cd}^{2+}\right)^{35}$ produces $E_{1 / 2}{ }^{0}\left(\mathrm{M}^{\mathrm{n}+} / \mathrm{M}\right)$ of $-2.91 \mathrm{~V}(-2.77 \mathrm{~V}$ if including the Trouton entropy), i.e. an error of 0.04 $\mathrm{V}(4 \mathrm{~kJ} / \mathrm{mol})$ vs. the experimental potential of $-2.87 \mathrm{~V}$ when using Equation (4) and the consensus $\Delta \mathrm{H}_{\mathrm{vap}}$ $=153 \mathrm{~kJ} / \mathrm{mol}$ for $\mathrm{Ca}^{2+}$. If the value $-1593 \mathrm{~kJ} / \mathrm{mol}$ is in error, it must be caused by $\Delta \mathrm{H}_{\mathrm{vap}}$ also being wrong, ${ }^{43}$ as the entropy contributions are too small to make a difference. For $\mathrm{Cd}^{2+}$, application of Equation (4) using $\Delta \mathrm{H}_{\mathrm{vap}}=100 \mathrm{~kJ} / \mathrm{mol}$ with the Trouton entropy gives $-0.39 \mathrm{~V}$, without it gives $-0.52 \mathrm{~V}$, compared to the experimental $-0.40 \mathrm{~V}$, suggesting an error in the relative $\Delta \mathrm{G}_{\mathrm{hyd}}$ of $\sim 12 \mathrm{~kJ} / \mathrm{mol}$.

Using the thermochemical cycle of Equation (4) as a test of accuracy, errors larger than $0.2 \mathrm{~V}$ are found for $\mathrm{Ho}^{2+}(-0.23 \mathrm{~V}), \mathrm{Pm}^{2+}(0.30 \mathrm{~V}), \mathrm{Ra}^{2+}(-0.28 \mathrm{~V})$, and $\mathrm{U}^{3+}(-0.33 \mathrm{~V})$, which can be considered particularly uncertain. This probably relates to errors in the measurements of the heats of vaporization, as discussed previously ${ }^{43}$, or to these metals deviating from Trouton's rule regarding $\Delta \mathrm{S}_{\mathrm{vap}}{ }^{0}$. In this context it is interesting that all these four metals are very heavy $(Z \geq 61)$. As more accurate data arrive at higher accuracy, the cycle and approximation in Equation (4) will probably become more valuable.

Among the new values identified in this work, those of the $\mathrm{M}^{3+}$ ions of the $4 \mathrm{~d}$ and $5 \mathrm{~d}$ transition series are particularly interesting. The new free energies of hydration for $4 \mathrm{~d}$ metal ions include $\mathrm{Nb}^{3+}(-$ $4165 \mathrm{~kJ} / \mathrm{mol}), \mathrm{Mo}^{3+}(-4250 \mathrm{~kJ} / \mathrm{mol}), \mathrm{Tc}^{2+}(-1776 \mathrm{~kJ} / \mathrm{mol}), \mathrm{Ru}^{2+}(-2000 \mathrm{~kJ} / \mathrm{mol})$, and $\mathrm{Rh}^{3+}(-4450 \mathrm{~kJ} / \mathrm{mol})$. The $5 \mathrm{~d}$ metal ions include $\mathrm{Ta}^{3+}(-4162 \mathrm{~kJ} / \mathrm{mol}), \mathrm{W}^{3+}(-4306 \mathrm{~kJ} / \mathrm{mol}), \mathrm{Re}^{3+}(-4298 \mathrm{~kJ} / \mathrm{mol})$, and $\mathrm{Ir}^{3+}(-4150$ 
$\mathrm{kJ} / \mathrm{mol}$ ). Many of these are important to homogenous catalysis and in materials, but are also important in their own right for understanding the $4 \mathrm{~d}$ and $5 \mathrm{~d}$ trend chemistry.

As an example, $\operatorname{Ir}^{3+}(\mathrm{aq})$ is one of the most inert systems in water with an extremely slow exchange of water ligands ${ }^{56}$ and has been studied in detail both theoretically and experimentally. ${ }^{57}$ While one expects $\Delta \mathrm{G}_{\mathrm{hyd}}$ to correlate with the lifetime of the complex (stronger hydration for higher charge and ligand field stabilization also gives slower ligand exchange), the new value in Table 1 of $-4150 \mathrm{~kJ} / \mathrm{mol}$ is not remarkably high in comparison to other $\mathrm{M}^{3+}$ ions, and thus the special inertness of $\operatorname{Ir}^{3+}(\mathrm{aq})$, which is a kinetic rather than thermodynamic phenomenon, has to be due to other features of the ion.

It is also worth noticing the experimentally elusive, highly unstable $\left(\mathrm{E}\left(\mathrm{Sc}^{3+} / \mathrm{Sc}^{2+}=-2.30 \mathrm{~V}\right)\right.$ but theoretically interesting $\mathrm{Sc}^{2+}$ with [Ar] $3 \mathrm{~d}^{1}$ configuration. $\mathrm{Sc}^{2+}$ has $\Delta \mathrm{G}_{\mathrm{hyd}}=-1745 \mathrm{~kJ} / \mathrm{mol}$, which is well in trend with $\Delta \mathrm{G}_{\mathrm{hyd}}$ for $\mathrm{Ti}^{2+}(-1887 \mathrm{~kJ} / \mathrm{mol})$ and $\mathrm{V}^{2+}(-1913 \mathrm{~kJ} / \mathrm{mol})$.

Main anomalies. Anomalies can be identified from the trend chemistry. Whereas the variations in the gas phase are exclusively due to electronic structure of the bare ions and atoms, variations in chemical composition of the hydrated states are possible. Such variations may affect the trends resulting from the effective nuclear charge and d/f-orbital occupation beyond the errors of the experimental data of the cycle and should thus be considered separately.

For the lanthanide $\Delta \mathrm{G}_{\text {hyd }}\left(\mathrm{M}^{3+}\right)$ series, $\Delta \mathrm{G}_{\text {hyd }}$ for $\mathrm{Gd}^{3+}$ is $-3415 \mathrm{~kJ} / \mathrm{mol}$ when computed using the cycle with the consensus $\Delta \mathrm{H}_{\mathrm{vap}}$ of $302 \mathrm{~kJ} / \mathrm{mol}^{43}$ This $\Delta \mathrm{G}_{\mathrm{hyd}}$ value is irregular by not following a smooth linear decrease in $\Delta \mathrm{G}_{\mathrm{hyd}}\left(\mathrm{M}^{3+}\right)$ (Supporting Information, Figure S1). From this, and trusting the measured ionization potentials listed in NIST, one can conclude that either the reduction potential or $\Delta \mathrm{H}_{\mathrm{vap}}$ of Gd is incorrect. The electronic structures, sizes, and reduction potentials are similar, and thus the chemical composition is also expected to be similar for the lanthanides, except a change in effective hydration number from 9 to 8 in the series. Accordingly, the $\Delta \mathrm{H}_{\mathrm{vap}}$ of $\mathrm{Gd}$ is the most likely reason for the discrepancy, one can estimate a value of $\Delta \mathrm{H}_{\mathrm{vap}}$ is $400 \mathrm{~kJ} / \mathrm{mol}, 100 \mathrm{~kJ} / \mathrm{mol}$ more than the currently accepted value, assuming that the reduction potential is correctly reported.

Also using the trend as quality control, the tabulated $\Delta \mathrm{G}_{\mathrm{hyd}}$ for $\mathrm{Yb}^{3+}$ by Marcus of $-3494 \mathrm{~kJ} / \mathrm{mol}$ should probably be corrected to $-3570 \pm 10 \mathrm{~kJ} / \mathrm{mol}$ on his scale, ${ }^{8}$ and the value for $\mathrm{Lu}^{3+}$ of $-3545 \mathrm{~kJ} / \mathrm{mol}$ should be close to $-3600 \mathrm{~kJ} / \mathrm{mol}$ on the same scale. Similarly, the value for $\mathrm{Pd}^{2+}$ tabulated by Noyes ($573 \mathrm{kcal} / \mathrm{mol}=-2397 \mathrm{~kJ} / \mathrm{mol})^{29}$ is substantially too negative by $400 \mathrm{~kJ} / \mathrm{mol}$ or so, and is probably a misprint that should have been $-473 \mathrm{kcal} / \mathrm{mol}$. 


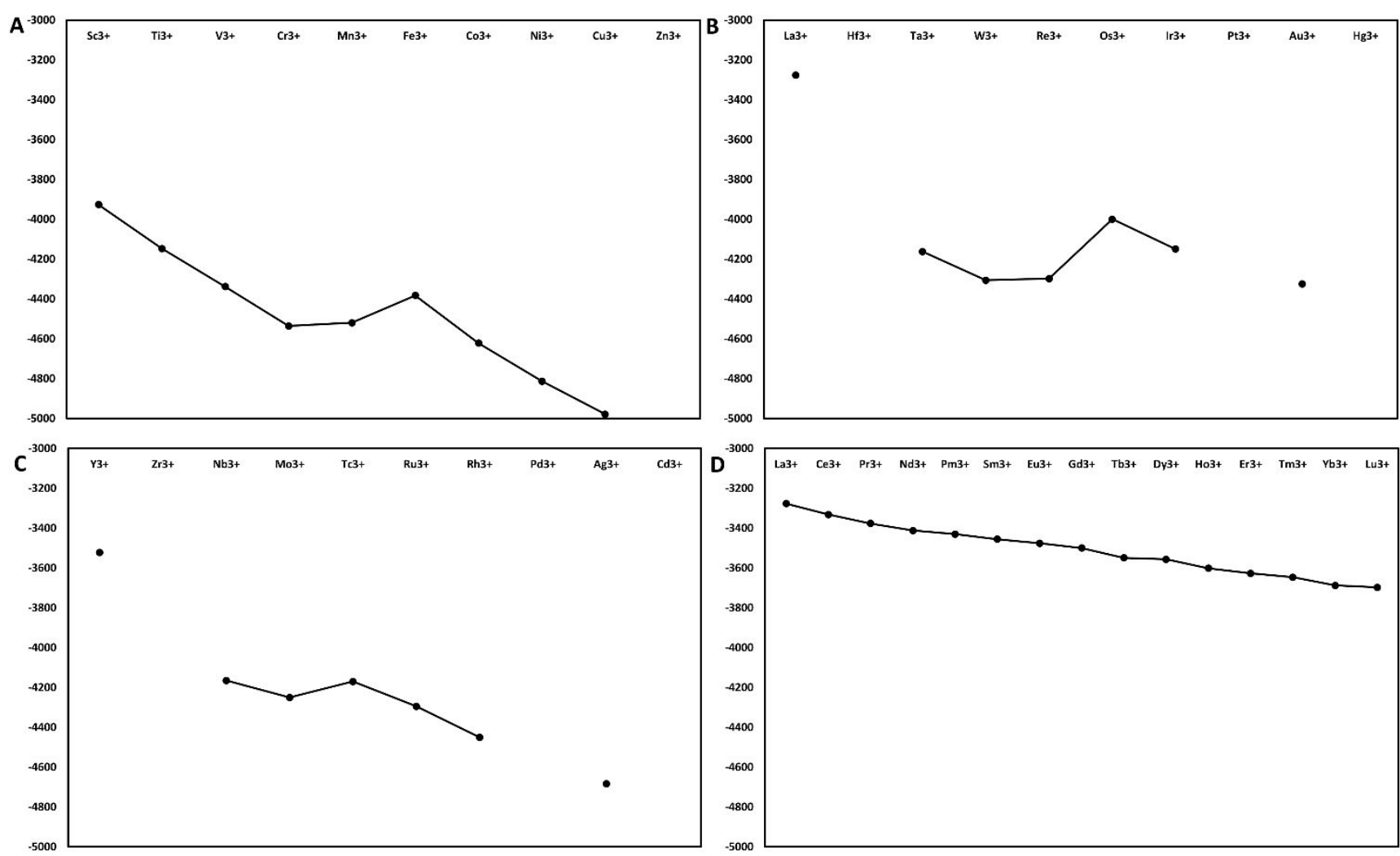

Figure 3. Trends in thermochemically consistent hydration free energies of $\mathrm{M}^{3+}$ ions of $\mathbf{A}$ ) the $3 \mathrm{~d}$ transition series; B) the $5 \mathrm{~d}$ transition series; C) the $4 \mathrm{~d}$ transition series; D) the lanthanides.

Among other interesting variations, the new value for $\mathrm{Ru}^{2+}(-2000 \mathrm{~kJ} / \mathrm{mol})$ is $72 \mathrm{~kJ} / \mathrm{mol}$ smaller than $\Delta \mathrm{G}_{\mathrm{hyd}}$ for $\mathrm{Fe}^{2+}(-1928 \mathrm{~kJ} / \mathrm{mol})$. However, the new value for $\mathrm{Tc}^{2+}(-1776 \mathrm{~kJ} / \mathrm{mol})$ is $72 \mathrm{~kJ} / \mathrm{mol}$ less negative than the value for $\mathrm{Mn}^{2+}(-1848 \mathrm{~kJ} / \mathrm{mol})$. This curious difference is not due to a relative change in d-orbital occupation and ligand field stabilization energy, as the change from high-spin $\mathrm{Mn}^{2+} / \mathrm{Fe}^{2+}$ to low-spin $\mathrm{Tc}^{2+} / \mathrm{Ru}^{2+}$ is similar. The $\mathrm{t}_{2 \mathrm{~g}}{ }^{6}$ state of $\mathrm{Ru}^{2+}$ is of course particularly stable but whereas the $3 \mathrm{~d}$ ions are invariably 6-coordinated, the assumption of pseudo-octahedral geometry may break down for the $4 \mathrm{~d}$ ions because coordination numbers are variable and not generally well established ${ }^{8,55}$, potentially explaining this difference. The $\mathrm{Ru}^{2+} / \mathrm{Ru}^{3+}$ potential has been studied using the standard Born Haber cycle for $\mathrm{M}^{2+/ 3+} .{ }^{58}$ It was estimated that $\Delta \mathrm{G}_{\text {hyd }}\left(\mathrm{Ru}^{3+}\right)-\Delta \mathrm{G}_{\mathrm{hyd}}\left(\mathrm{Ru}^{2+}\right)$ is $\sim 24 \mathrm{eV}$ or about $2315 \mathrm{~kJ} / \mathrm{mol}$. Using the new value for $\mathrm{Ru}^{2+}(-2000 \mathrm{~kJ} / \mathrm{mol})$ and the potential of $+0.24 \mathrm{~V}$ by Bratsch ${ }^{52}$, one calculates $\Delta \mathrm{G}_{\text {hyd }}\left(\mathrm{Ru}^{3+}\right)$ $=-4295 \mathrm{~kJ} / \mathrm{mol}$, which has been included in Table 1. This gives an experimental difference in $\Delta \mathrm{G}_{\text {hyd }}$ of $2295 \mathrm{~kJ} / \mathrm{mol}$, the minor difference being due to the choice of SHE (4.44 V vs. $\left.4.28 \mathrm{~V}^{58}\right)$.

Trend chemistry. It is important to understand the periodic trends in the properties of metal ions. When both $\mathrm{M}^{2+}$ and $\mathrm{M}^{3+}$ values of $\Delta \mathrm{G}_{\text {hyd }}$ are available, the contribution of the difference in $\Delta \mathrm{G}_{\mathrm{hyd}}\left(\mathrm{M}^{3+}\right)-\Delta \mathrm{G}_{\mathrm{hyd}}\left(\mathrm{M}^{2+}\right)$ to the chemically important $E_{1 / 2}{ }^{0}\left(\mathrm{M}^{3+} / \mathrm{M}^{2+}\right)$ potential can be assessed. Previous 
analysis suggests that the variations in $\Delta \mathrm{G}_{\text {hyd }}\left(\mathrm{M}^{3+}\right)-\Delta \mathrm{G}_{\mathrm{hyd}}\left(\mathrm{M}^{2+}\right)$ (the hydration energy effects) contributes to the same extent to the variation in $E_{1 / 2}^{0}\left(\mathrm{M}^{3+} / \mathrm{M}^{2+}\right)$ as the variations in the ionization potentials (electronic structure) of the gas-phase atomic M. At first instance, this seems unsurprising since they are both large in energy terms. However, the variations in ionization energy and $\Delta \mathrm{G}_{\mathrm{hyd}}\left(\mathrm{M}^{3+}\right)-\Delta \mathrm{G}_{\text {hyd }}\left(\mathrm{M}^{2+}\right)$ hide important ligand field effects that contribute to the net observed potential; thus for example, the $\Delta \mathrm{G}_{\text {hyd }}\left(\mathrm{M}^{3+}\right)$ and $\Delta \mathrm{G}_{\text {hyd }}\left(\mathrm{M}^{2+}\right)$ trends have their humps shifted due to the difference of one d-electron, which changes the position of the maximal and minimal ligand field stabilization energy ${ }^{35,59}$. Variations in the relative importance of $\Delta \mathrm{G}_{\mathrm{hyd}}\left(\mathrm{M}^{3+}\right)-\Delta \mathrm{G}_{\mathrm{hyd}}\left(\mathrm{M}^{2+}\right)$ and the differential ionization energy thus relate strongly to the different electronic splitting of bare atomic ions vs. octahedral aqueous ions. For larger ions, such analysis is complicated by coordination numbers larger than 6 .

Figure 3 shows the thermochemically consistent values of $\Delta \mathrm{G}_{\text {hyd }}\left(\mathrm{M}^{3+}\right)$ for the $3 \mathrm{~d}, 4 \mathrm{~d}, 5 \mathrm{~d}$, and lanthanide transition series, including both the new values obtained in this work and the recently reported values. ${ }^{35}$ Since these values (the last two columns of Table 1 and Table 2) are all thermochemically consistent (consistent with their respective thermochemical cycles and using the same reference states), they can be applied to trend chemistry as done in Figure 3. The corresponding trends for the $3 \mathrm{~d}$ and $4 \mathrm{~d}$ series of the $\mathrm{M}^{2+}$ ions are shown in Figure S2 and Figure S3, respectively, showing how $\mathrm{Sc}^{2+}$ fits excellently in the overall trend, and showing the expected trend of $\mathrm{Tc}^{2+}$ and $\mathrm{Ru}^{2+}$ in the $4 \mathrm{~d}$ series. The overall trends follow the patterns seen for enthalpies of hydration, such as $\Delta \mathrm{H}_{\text {hyd }}\left(\mathrm{M}^{2+}\right)^{60}$, due to the similar hydration entropy of the species, which is dominated by the vibrational entropy of the M-O bonds of the first solvation sphere.

Among the most interesting observations from Figure 3 is i) the generally expected observation that the hydration free energy becomes more negative with increasing effective nuclear charge towards the right of each series. ii) that this tendency becomes less pronounced from $3 \mathrm{~d}$ to $4 \mathrm{~d}$ (Figure 3A-3C), from $4 \mathrm{~d}$ to $5 \mathrm{~d}$ (Figure 3B-3C), and from $5 \mathrm{~d}$ to the lanthanides (Figure 3B-3D). Thus the $\Delta \mathrm{G}_{\text {hyd }}\left(\mathrm{M}^{3+}\right.$ ) lanthanides vary by only $420 \mathrm{~kJ} / \mathrm{mol}$ from $\mathrm{La}$ to $\mathrm{Lu}$, and the trend is very linear, showing that variations in properties and chemical composition are minor for this series (Figure 3D. Illustrating this point, most lanthanides having $E_{1 / 2}^{0}\left(\mathrm{M}^{3+} / \mathrm{M}\right)$ of $-2.3 \mathrm{~V}$. The notable exception and major outlier is Eu with $E_{1 / 2}\left(\mathrm{M}^{3+} / \mathrm{M}\right)$ of $\left.-1.99 \mathrm{~V} .{ }^{52} \mathrm{iii}\right)$ The trends of the three d-transition series trend are all disrupted by a hump of approximately $100 \mathrm{~kJ} / \mathrm{mol}$ in the middle of the series, which is due to d-orbital occupation effects. Specifically, for the $3 \mathrm{~d}$ series (Figure 3A), the hump occurs with a local minimum at $\mathrm{Cr}^{3+}$, which has $\mathrm{t}_{2 \mathrm{~g}}{ }^{3}$ configuration and thus maximal ligand field stabilization energy for the high-spin aqua ions in the pseudo-octahedral $\left(\mathrm{O}_{\mathrm{h}}\right)$ ligand field of the first solvation sphere. Accordingly, the local maximum occurs 
at $\mathrm{Fe}^{3+}$, which has zero ligand field stabilization energy $\left(\mathrm{t}_{2 \mathrm{~g}}{ }^{3} \mathrm{e}_{\mathrm{g}}{ }^{2}\right)$. These findings are well in line in expectations from quantum chemical calculations. ${ }^{59}$

$\mathrm{Co}^{3+}(\mathrm{aq})$ generally thought to be the only low-spin ion of the $3 \mathrm{~d}$ series, and $\mathrm{Rh}^{3+}(\mathrm{aq})$ is accordingly clearly low-spin. However it has been argued that high-spin $\mathrm{Co}^{3+}(\mathrm{aq})$ is actually measured under most conditions, based on analysis of spin-crossover entropies, ligand substitution reactions and self-exchange electron transfer. ${ }^{54}$ Figure 3A supports our previous claim ${ }^{54}$ that $\mathrm{Co}^{3+}(\mathrm{aq})$ is in a highspin state as measured, since $\mathrm{Co}^{3+}(\mathrm{aq})$ falls near the background linear trend of the effective nuclear charge with the additional ligand field effect in good trend with $\mathrm{Fe}^{3+}, \mathrm{Ni}^{3+}$, and $\mathrm{Cu}^{3+}$, which are highspin (for $\mathrm{Cu}^{3+}$ this makes no difference as it has $\mathrm{t}_{2 \mathrm{~g}}{ }^{6} \mathrm{e}_{\mathrm{g}}{ }^{2}$ configuration regardless of the ligand field strength). The value for $\mathrm{Os}^{3+}$ is very high (Figure 3B) considering that it has higher effective nuclear charge and more occupied bonding d-orbitals than the metal ions preceding it in the series. In fact, lowspin assumption of the $5 \mathrm{~d}$ series would imply only one hump at $\mathrm{t}_{2 \mathrm{~g}}{ }^{6}\left(\mathrm{Ir}^{3+}\right)$ vs. two for the high-spin $3 \mathrm{~d}$ metal ions. The $5 \mathrm{~d}$ series looks more like a high-spin than a low-spin series, and changes in chemical composition or solvation number ${ }^{55}$ may happen from $\mathrm{W}^{3+} / \mathrm{Re}^{3+}$ to $\mathrm{Os}^{3+}$ if the heats of vaporization are accurate. $4 \mathrm{~d}$ and $5 \mathrm{~d}$ metal ions such as rhodium and molybdenum are known to form cluster aqua ions, and we thus note that the data for the $5 \mathrm{~d}$ metal ions are overall the most scarce and uncertain.

Again, Figure 3C reveals the $\mathrm{Ru}^{3+} / \mathrm{Tc}^{3+}$ anomaly that was also apparent from group-wise comparison, with the maximum occurring period-wise already at $\mathrm{Tc}^{3+} \mathrm{vs}$. $\mathrm{Ru}^{3+}$ which would be expected for six-coordination. Considering the accuracy of the data, this suggests a change in geometry of electronic structure occurring at $\mathrm{Tc}^{3+}$. Two main possibilities can be envisioned: One is a change in solvation number and thus d-orbital stabilization effects occurring with $\mathrm{Tc}^{3+}$, i.e. that this ion has a higher coordination number than 6 . The other possible explanation is that $\mathrm{Tc}^{3+}(\mathrm{aq})$ is in a strongly Jahn-Teller distorted high-spin $\mathrm{d}^{4}$ state, while the later ions of the series are low-spin. The fact that Jahn-Teller distortion would stabilize the high-spin state of $\mathrm{Tc}^{3+}(\mathrm{aq})$ to make it the perhaps only $\mathrm{M}^{3+}(\mathrm{aq})$ high-spin state of the $4 \mathrm{~d}$ series is worth exploring further. The same occurs for $\mathrm{Mn}^{3+}(\mathrm{aq})$ of course, but in this case the neighbor ions are all high-spin thus making the Jahn-Teller effect on the trend smaller.

Main determinants of redox stability of metal ions in water. With the consistent data now available in Table 1 and Table 2, we can address a final, important question of how the observed standard reduction potentials $E_{1 / 2} 0\left(\mathrm{M}^{\mathrm{n}+} / \mathrm{M}\right)$, which determine the relative activity and stability of the metal ions in water, are caused by contributions from the three terms of Equation (4). In this consideration the effect of the ionization energy represents the intrinsic vacuum electronic structure contribution to $E_{1 / 2}^{0}\left(\mathrm{M}^{\mathrm{n}+} / \mathrm{M}\right)$, with a larger value reflecting more stable electrons in the metal atom, favoring reduction. 
the heat of vaporization represents the intrinsic stability of the bulk metal material via the metal-metal bonding strength. These two terms are always positive and favor reduction to the metal state. The last term, the free energy of hydration, represents the oxidized ion's affinity for the water phase in the electrochemical system, is always negative and favors oxidation. As evident from the analysis in this work, despite the range of tens of $\mathrm{eV}$ in the ionization and hydration free energies, the latter term almost completely cancels the first two terms to give standard reduction potentials of only $\pm 3 \mathrm{~V}$.
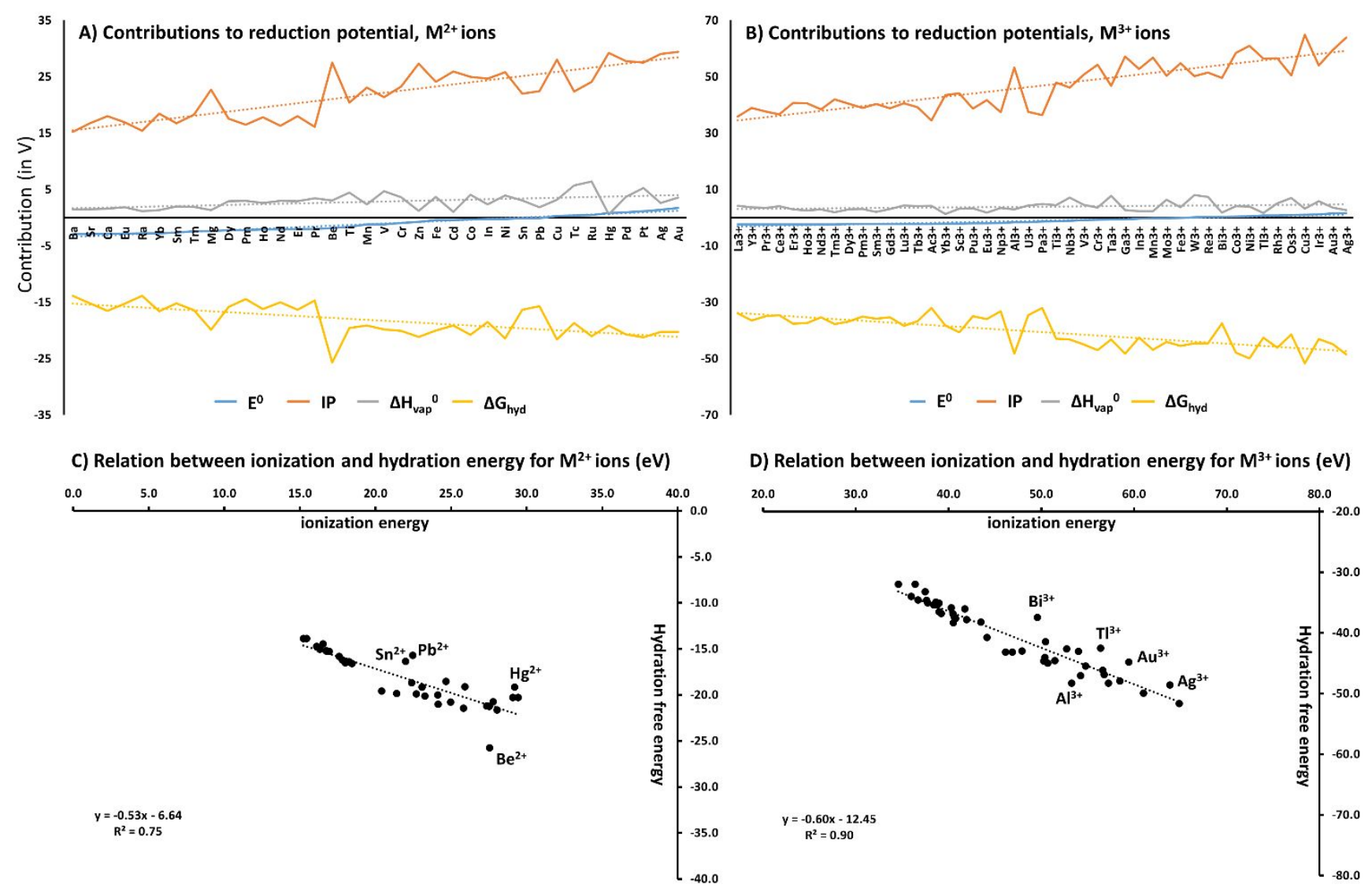

Figure 4. A) Contributions of ionization energy, free energy of hydration, and vaporization enthalpy to the standard reduction potentials of $\mathrm{M}^{2+}$ ions. B) Same for $\mathrm{M}^{3+}$ ions. C) Relation between ionization energy and hydration free energy for $\mathrm{M}^{2+}$ ions. D) same for $\mathrm{M}^{3+}$ ions. Notable outliers are main group elements and noble metals as marked.

To understand the important variations in this overall tendency, the exact contribution for each metal is summarized in Figure 4, using the data in Supporting information Table S1 and Table S2. Figure 4A shows the contributions for the $\mathrm{M}^{2+}$ ions, whereas Figure $4 \mathrm{~B}$ shows them for the $\mathrm{M}^{3+}$ ions. The metal ions have been ordered according to the electrochemical (activity) series specific to each 
oxidation state, i.e. according to $E_{1 / 2}{ }^{0}\left(\mathrm{M}^{\mathrm{n}+} / \mathrm{M}\right)$. The correlation between the ionization potentials and the hydration free energies are very evident as seen from Figure 4C and 4D. In contrast, $\Delta \mathrm{H}_{\mathrm{vap}}$ does not correlate with ionization energies at all (Figure S4). Accordingly, we can conclude that $\Delta \mathrm{H}_{\mathrm{vap}}$, which measures the metal self-affinity or metal stability, is a very important determinant of deviations from the expected trends in reduction potentials; these contributions are colored gray in Figure 4A and 4B. It can be seen that outliers from the trends are mainly due to main group elements and noble metals.

This analysis helps understand why $\mathrm{Eu}^{3+}$ has a substantially less negative $E_{1 / 2}{ }^{0}\left(\mathrm{M}^{3+} / \mathrm{M}\right)=-1.99 \mathrm{~V}$ than the remaining lanthanides (typically -2.3 V). Figure S5 shows the correlation between ionization energy and $\Delta \mathrm{G}_{\mathrm{hyd}}$ for the lanthanides, showing that $\mathrm{Eu}^{3+}$ and $\mathrm{Lu}^{3+}$ in the middle and end of the series are outliers in this relationship, which is certainly an f-orbital occupation effect in the water ligand field distinct from the bare ion. One would expect from the linear relationship alone that $\mathrm{Eu}^{3+}$ had a 200 $\mathrm{kJ} / \mathrm{mol}$ more negative hydration free energy considering its ionization energy. The reason is, arguably, a combination of the change in solvation number rom 9 to 8 in the lanthanide series combined with a low ligand field stabilization energy of the split f-orbitals in the field of the high coordination number.

As another illustrative example, $\mathrm{Sc}^{3+}(-2.08 \mathrm{~V})$ and $\mathrm{Pu}^{3+}(-2.03 \mathrm{~V})$ have very similar aqueous reduction potentials but for extremely different reasons. While they have very similar metal vaporization enthalpies, for Sc the ionization energy required to produce the trivalent ion from the metal is $5.5 \mathrm{eV}$ larger than for $\mathrm{Pu}$; in contrast the hydration free energy is about $5.8 \mathrm{eV}$ less negative for $\mathrm{Pu}^{3+}$ than for $\mathrm{Sc}^{3+}$, such that the two tendencies almost cancel. In other words, there are two completely different ways to attain a similar reduction potential, a fact that may be of interest to the rational design of electrocatalysts.

\section{Conclusions}

In an electrochemical measurement, the energy required to release the metal atoms from the bulk metal during the oxidation process is a major contributor to the observed potentials. However, this free energy can be described accurately by the enthalpy of vaporization of the metal, partly because the entropy of vaporization is relatively small and similar for most metals, a fact known as Trouton's rule. This principle has been used in the present paper to calculate many new, thermochemically consistent free energies of hydration of $\mathrm{M}^{3+}$ and $\mathrm{M}^{2+}$ ions, which add to the previously reported values. The values are shown to be accurate with a trend accuracy of $\mathrm{R}^{2}=0.99-1.00$ and a numerical accuracy of $\sim 10 \mathrm{~kJ} / \mathrm{mol}$. Some implications and trends of the new values and their contributions from each term in the cycle of 
Equation (4) are discussed. It is hoped that the new values and the relationships identified will be of value in future studies of these metal ions and their aqueous chemistry.

Acknowledgements. The Danish Council for Independent Research | Natural sciences (FNU) (grant 272-08-0041) is acknowledged for supporting this work.

Supporting Information. The Supporting Information file contains data with experimental standard half reduction potentials (in V) and first, second, and third ionization potentials (in eV) used for the calculations done in this work. 


\section{References}

(1) Zhang, Y.; Cremer, P. S. Interactions between Macromolecules and Ions: The Hofmeister Series. Curr. Opin. Chem. Biol. 2006, 10, 658-663.

(2) Collins, K. D. Ion Hydration: Implications for Cellular Function, Polyelectrolytes, and Protein Crystallization. Biophys. Chem. 2006, 119, 271-281.

(3) Rode, B. M.; Schwenk, C. F.; Hofer, T. S.; Randolf, B. R. Coordination and Ligand Exchange Dynamics of Solvated Metal Ions. Coord. Chem. Rev. 2005, 249, 2993-3006.

(4) Kepp, K. P. Alzheimer's Disease: How Metal Ions Define $\beta$-Amyloid Function. Coord. Chem. Rev. 2017, 351, 127-159.

(5) Carter, K. P.; Young, A. M.; Palmer, A. E. Fluorescent Sensors for Measuring Metal Ions in Living Systems. Chem. Rev. 2014, 114, 4564-4601.

(6) Ohtaki, H.; Radnai, T. Structure and Dynamics of Hydrated Ions. Chem. Rev. 1993, 93, 11571204.

(7) Woodson, S. A. Metal Ions and RNA Folding: A Highly Charged Topic with a Dynamic Future. Curr. Opin. Chem. Biol. 2005, 9, 104-109.

(8) Marcus, Y. Ions in Solution and Their Solvation, 1st ed.; Wiley Online Library: New Jersey, 2015.

(9) Asthagiri, D.; Pratt, L. R.; Paulaitis, M. E.; Rempe, S. B. Hydration Structure and Free Energy of Biomolecularly Specific Aqueous Dications, Including $\mathrm{Zn}^{2+}$ and First Transition Row Metals. J. Am. Chem. Soc. 2004, 126, 1285-1289.

(10) Hud, N. V; Smith, F. W.; Anet, F. A. L.; Feigon, J. The Selectivity for $\mathrm{K}^{+}$versus $\mathrm{Na}^{+}$in DNA Quadruplexes Is Dominated by Relative Free Energies of Hydration: A Thermodynamic Analysis by 1H NMR. Biochemistry 1996, 35, 15383-15390.

(11) Sahu, S.; Di Ventra, M.; Zwolak, M. Dehydration as a Universal Mechanism for Ion Selectivity in Graphene and Other Atomically Thin Pores. Nano Lett. 2017, 17, 4719-4724.

(12) Song, C.; Corry, B. Intrinsic Ion Selectivity of Narrow Hydrophobic Pores. J. Phys. Chem. B 2009, 113, 7642-7649.

(13) Teppen, B. J.; Miller, D. M. Hydration Energy Determines Isovalent Cation Exchange Selectivity by Clay Minerals. Soil Sci. Soc. Am. J. 2006, 70, 31-40. 
(14) Trasatti, S. On the Concept and the Possibility of Experimental Determination of Absolute Electrode Potentials. J. Chem. Phys. 1978, 69, 2938-2939.

(15) Trasatti, S. The Concept of Absolute Electrode Potential an Attempt at a Calculation. $J$. Electroanal. Chem. Interfacial Electrochem. 1974, 52, 313-329.

(16) Latimer, W. M. Single Ion Free Energies and Entropies of Aqueous Ions. J. Chem. Phys. 1955, 23, 90-92.

(17) Latimer, W. M.; Pitzer, K. S.; Slansky, C. M. The Free Energy of Hydration of Gaseous Ions, and the Absolute Potential of the Normal Calomel Electrode. In Molecular Structure And Statistical Thermodynamics: Selected Papers of Kenneth S Pitzer; World Scientific, 1993; pp $485-489$.

(18) Jørgensen, C. K. Theoretical Chemistry of Rare Earths. Handb. Phys. Chem. rare earths 1979, $3,111-169$.

(19) Marenich, A. V; Ho, J.; Coote, M. L.; Cramer, C. J.; Truhlar, D. G. Computational Electrochemistry: Prediction of Liquid-Phase Reduction Potentials. Phys. Chem. Chem. Phys. 2014, 16, 15068-15106.

(20) Ho, J. Are Thermodynamic Cycles Necessary for Continuum Solvent Calculation of pKas and Reduction Potentials? Phys. Chem. Chem. Phys. 2015, 17, 2859-2868.

(21) Chaudhari, M. I.; Pratt, L. R.; Rempe, S. B. Utility of Chemical Computations in Predicting Solution Free Energies of Metal Ions. Mol. Simul. 2018, 44, 110-116.

(22) Sun, D.; Lakkaraju, S. K.; Jo, S.; MacKerell Jr, A. D. Determination of Ionic Hydration Free Energies with Grand Canonical Monte Carlo/Molecular Dynamics Simulations in Explicit Water. J. Chem. Theory Comput. 2018, 14, 5290-5302.

(23) Remsing, R. C.; Duignan, T. T.; Baer, M. D.; Schenter, G. K.; Mundy, C. J.; Weeks, J. D. Water Lone Pair Delocalization in Classical and Quantum Descriptions of the Hydration of Model Ions. J. Phys. Chem. B 2018, 122, 3519-3527.

(24) Lamoureux, G.; Roux, B. Absolute Hydration Free Energy Scale for Alkali and Halide Ions Established from Simulations with a Polarizable Force Field. J. Phys. Chem. B 2006, 110, $3308-3322$.

(25) Aqvist, J. Ion-Water Interaction Potentials Derived from Free Energy Perturbation Simulations. 
J. Phys. Chem. 1990, 94, 8021-8024.

(26) Sitkoff, D.; Sharp, K. A.; Honig, B. Accurate Calculation of Hydration Free Energies Using Macroscopic Solvent Models. J. Phys. Chem. 1994, 98, 1978-1988.

(27) Jensen, K. P. Improved Interaction Potentials for Charged Residues in Proteins. J. Phys. Chem. B 2008, 112, 1820-1827.

(28) Jensen, K. P.; Jorgensen, W. L. Halide, Ammonium, and Alkali Metal Ion Parameters for Modeling Aqueous Solutions. J. Chem. Theory Comput. 2006, 2, 1499-1509.

(29) Noyes, R. M. Thermodynamics of Ion Hydration as a Measure of Effective Dielectric Properties of Water. J. Am. Chem. Soc. 1962, 84, 513-522.

(30) Rosseinsky, D. R. Electrode Potentials and Hydration Energies. Theories and Correlations. Chem. Rev. 1965, 65, 467-490.

(31) Fawcett, W. R. Thermodynamic Parameters for the Solvation of Monatomic Ions in Water. $J$. Phys. Chem. B 1999, 103, 11181-11185.

(32) Rizkalla, E. N.; Choppin, G. R. Hydration and Hydrolysis of Lanthanides. Handb. Phys. Chem. rare earths 1991, 15, 393-442.

(33) Marcus, Y. Thermodynamics of Solvation of Ions. Part 5. Gibbs Free Energy of Hydration at 298.15 K. J. Chem. Soc. Faraday Trans. 1991, 87, 2995-2999.

(34) Marcus, Y. A Simple Empirical Model Describing the Thermodynamics of Hydration of Ions of Widely Varying Charges, Sizes, and Shapes. Biophys. Chem. 1994, 51, 111-127.

(35) Kepp, K. P. Thermochemically Consistent Free Energies of Hydration for Di-and Trivalent Metal Ions. J. Phys. Chem. A 2018, 122, 7464-7471.

(36) Gomer, R.; Tryson, G. An Experimental Determination of Absolute Half-cell Emf's and Single Ion Free Energies of Solvation. J. Chem. Phys. 1977, 66, 4413-4424.

(37) Trasatti, S. The Absolute Electrode Potential: An Explanatory Note (Recommendations 1986). Pure Appl. Chem. 1986, 58, 955-966.

(38) Tissandier, M. D.; Cowen, K. A.; Feng, W. Y.; Gundlach, E.; Cohen, M. H.; Earhart, A. D.; Coe, J. V; Tuttle, T. R. The Proton's Absolute Aqueous Enthalpy and Gibbs Free Energy of Solvation from Cluster-Ion Solvation Data. J. Phys. Chem. A 1998, 102, 7787-7794. 
(39) Kelly, C. P.; Cramer, C. J.; Truhlar, D. G. Aqueous Solvation Free Energies of Ions and IonWater Clusters Based on an Accurate Value for the Absolute Aqueous Solvation Free Energy of the Proton. J. Phys. Chem. B 2006, 110, 16066-16081.

(40) Marcus, Y. The Thermodynamics of Solvation of Ions. Part 4.-Application of the Tetraphenylarsonium Tetraphenylborate (TATB) Extrathermodynamic Assumption to the Hydration of Ions and to Properties of Hydrated Ions. J. Chem. Soc. Faraday Trans. 1987, 83, 2985-2992.

(41) Duignan, T. T.; Baer, M. D.; Mundy, C. J. Understanding the Scale of the Single Ion Free Energy: A Critical Test of the Tetra-Phenyl Arsonium and Tetra-Phenyl Borate Assumption. $J$. Chem. Phys. 2018, 148, 222819.

(42) Pollard, T. P.; Beck, T. L. Re-Examining the Tetraphenyl-Arsonium/Tetraphenyl-Borate (TATB) Hypothesis for Single-Ion Solvation Free Energies. J. Chem. Phys. 2018, 148, 222830.

(43) Zhang, Y.; Evans, J. R. G.; Yang, S. Corrected Values for Boiling Points and Enthalpies of Vaporization of Elements in Handbooks. J. Chem. Eng. Data 2011, 56, 328-337.

(44) Zhan, C.-G.; Dixon, D. A. Absolute Hydration Free Energy of the Proton from First-Principles Electronic Structure Calculations. J. Phys. Chem. A 2001, 105, 11534-11540.

(45) Fawcett, W. R. The Ionic Work Function and Its Role in Estimating Absolute Electrode Potentials. Langmuir 2008, 24, 9868-9875.

(46) Farrell, J. R.; McTigue, P. Precise Compensating Potential Difference Measurements with a Voltaic Cell: The Surface Potential of Water. J. Electroanal. Chem. Interfacial Electrochem. 1982, 139, 37-56.

(47) Randles, J. E. B. The Real Hydration Energies of Ions. Trans. Faraday Soc. 1956, 52, 15731581.

(48) Krishtalik, L. I. The Surface Potential of Solvent and the Intraphase Pre-Existing Potential. Russ. J. Electrochem. 2008, 44, 43-49.

(49) Parfenyuk, V. I. Surface Potential at the Gas-aqueous Solution Interface. Colloid J. 2002, 64, $588-595$.

(50) Trouton, F. IV. On Molecular Latent Heat. London, Edinburgh, Dublin Philos. Mag. J. Sci. 1884, 18, 54-57. 
(51) John Rumble. CRC Handbook of Chemistry and Physics, 98th Edition; CRC Handbook of Chemistry and Physics; CRC Press LLC, 2017.

(52) Bratsch, S. G. Standard Electrode Potentials and Temperature Coefficients in Water at 298.15 K. J. Phys. Chem. Ref. Data 1989, 18, 1-21.

(53) Stark, J. G.; Wallace, H. G.; McGlashan, M. L. Chemistry Data Book; Murray London, 1982.

(54) Nielsen, M. T.; Moltved, K. A.; Kepp, K. P. Electron Transfer of Hydrated Transition-Metal Ions and the Electronic State of $\mathrm{Co}^{3+}(\mathrm{Aq})$. Inorg. Chem. 2018, 57, 7914-7924.

(55) Persson, I. Hydrated Metal Ions in Aqueous Solution: How Regular Are Their Structures? Pure Appl. Chem. 2010, 82, 1901-1917.

(56) Cusanelli, A.; Frey, U.; Richens, D. T.; Merbach, A. E. The Slowest Water Exchange at a Homoleptic Mononuclear Metal Center: Variable-Temperature and Variable-Pressure $17 \mathrm{O}$ NMR Study on $\left[\operatorname{Ir}\left(\mathrm{H}_{2} \mathrm{O}\right)_{6}\right]^{3+}$. J. Am. Chem. Soc. 1996, 118, 5265-5271.

(57) Carrera, F.; Torrico, F.; Richens, D. T.; Muñoz-Páez, A.; Martínez, J. M.; Pappalardo, R. R.; Marcos, E. S. Combined Experimental and Theoretical Approach to the Study of Structure and Dynamics of the Most Inert Aqua Ion $\left[\operatorname{Ir}\left(\mathrm{H}_{2} \mathrm{O}\right)_{6}\right]^{3+}$ in Aqueous Solution. J. Phys. Chem. B 2007, $111,8223-8233$.

(58) Jaque, P.; Marenich, A. V; Cramer, C. J.; Truhlar, D. G. Computational Electrochemistry: The Aqueous Ru3+|Ru2+ Reduction Potential. J. Phys. Chem. C 2007, 111, 5783-5799.

(59) Aakesson, R.; Pettersson, L. G. M.; Sandstroem, M.; Wahlgren, U. Ligand Field Effects in the Hydrated Divalent and Trivalent Metal Ions of the First and Second Transition Periods. J. Am. Chem. Soc. 1994, 116, 8691-8704.

(60) Atkins, P.; Overton, T. Shriver and Atkins' Inorganic Chemistry; Oxford University Press, USA, 2010. 


\section{Table of Content Graphic}

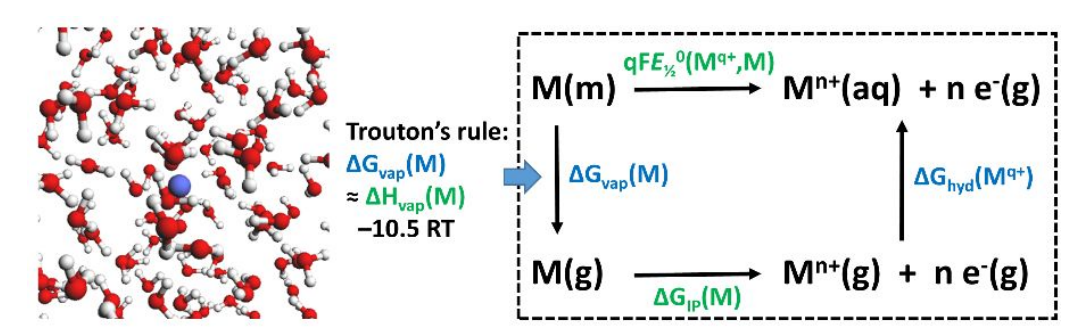




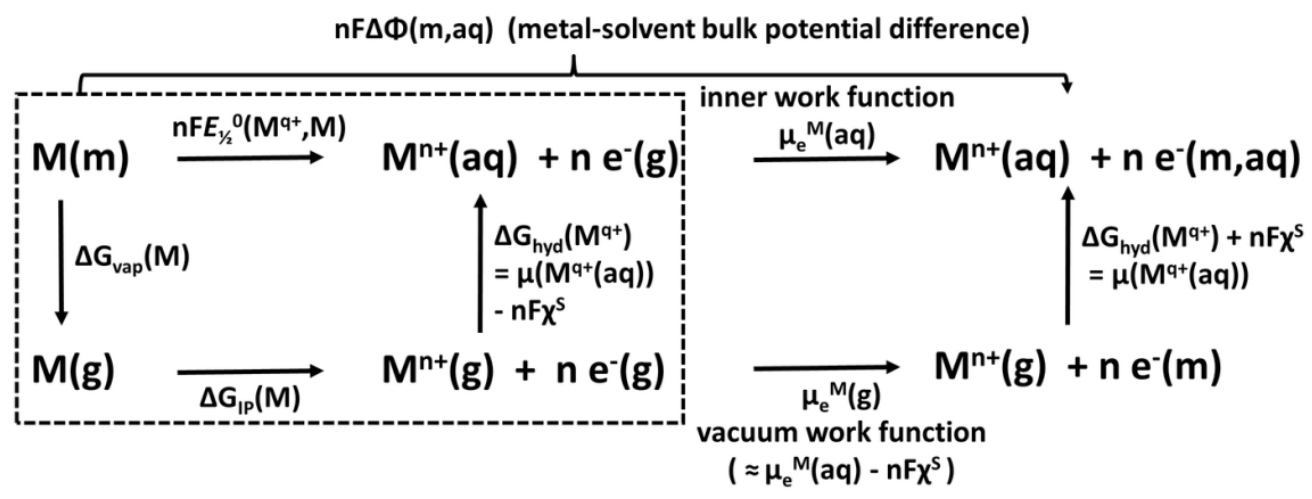

Figure 1

$118 \times 44 \mathrm{~mm}(300 \times 300$ DPI $)$ 

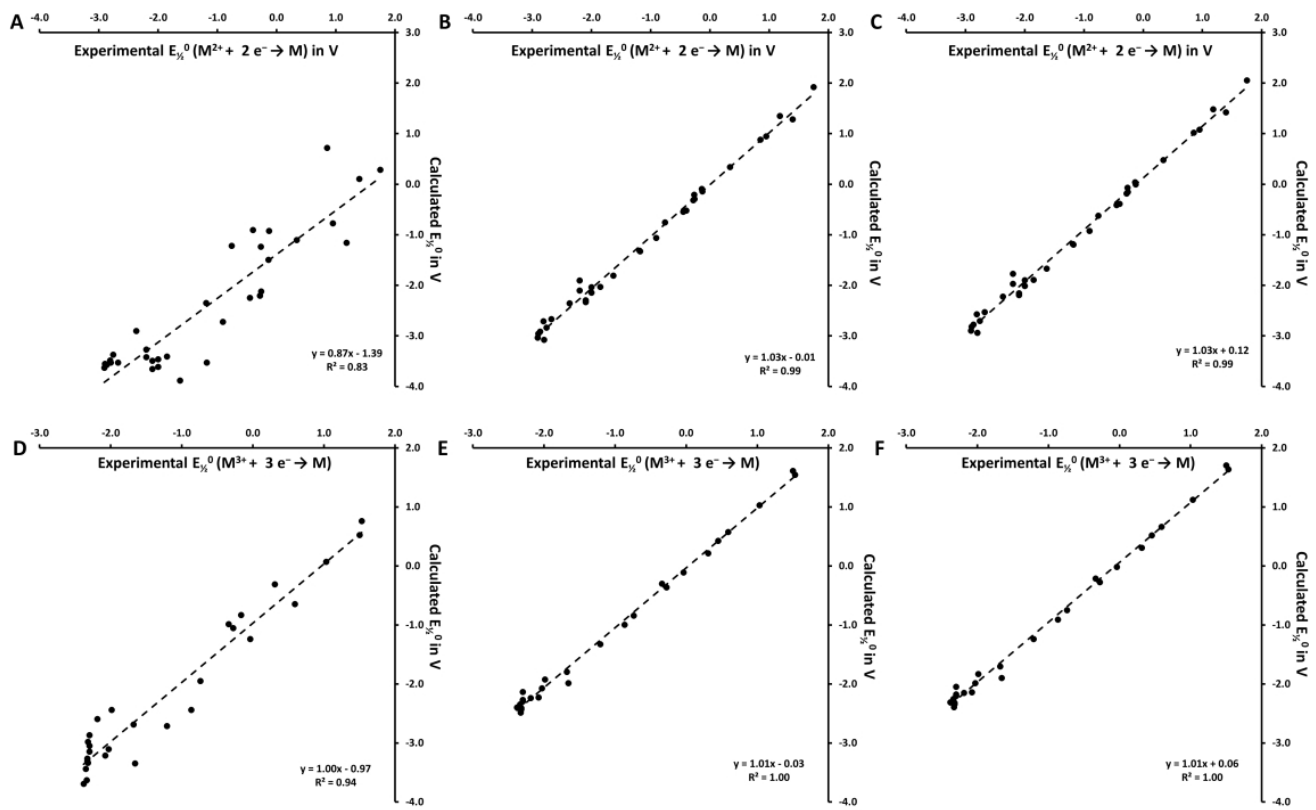

FIgure 2

$363 \times 228 \mathrm{~mm}(300 \times 300 \mathrm{DPI})$ 


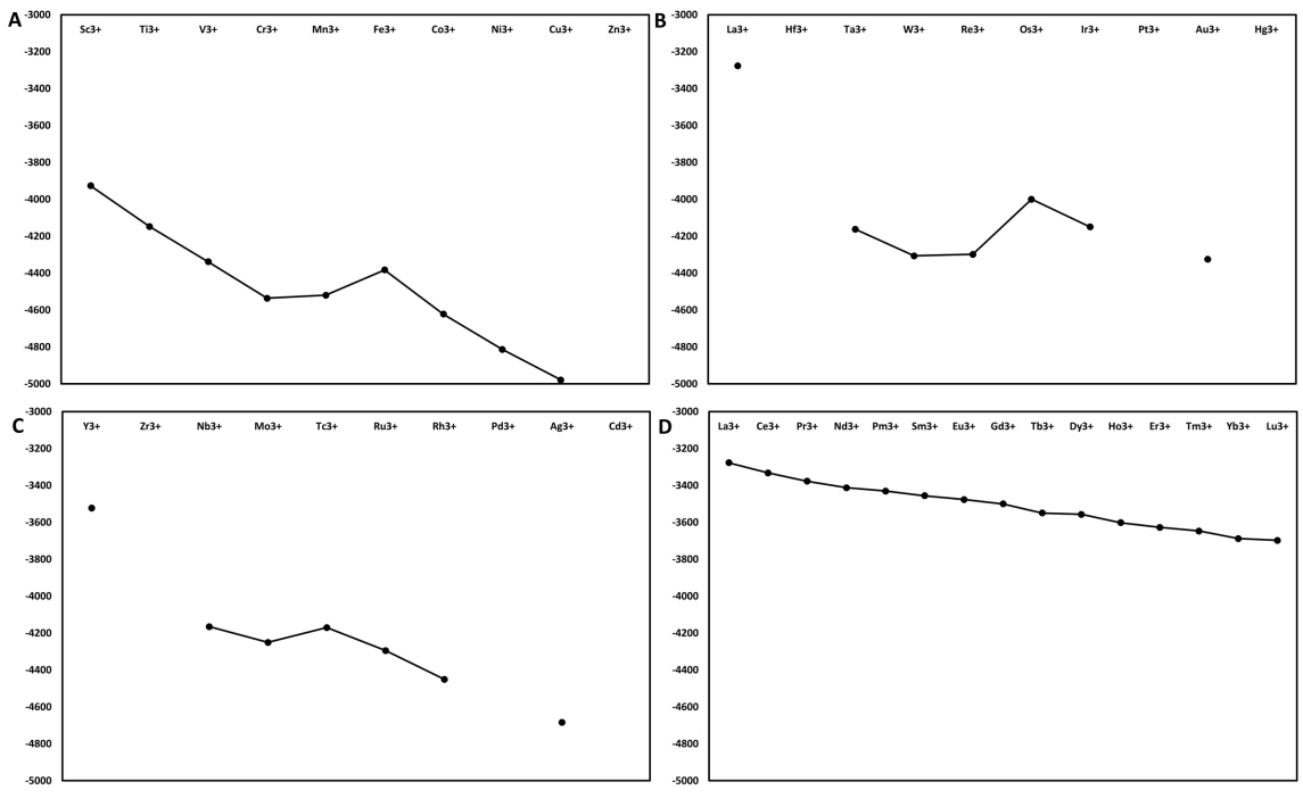

Figure 3

$218 \times 132 \mathrm{~mm}(300 \times 300$ DPI $)$ 


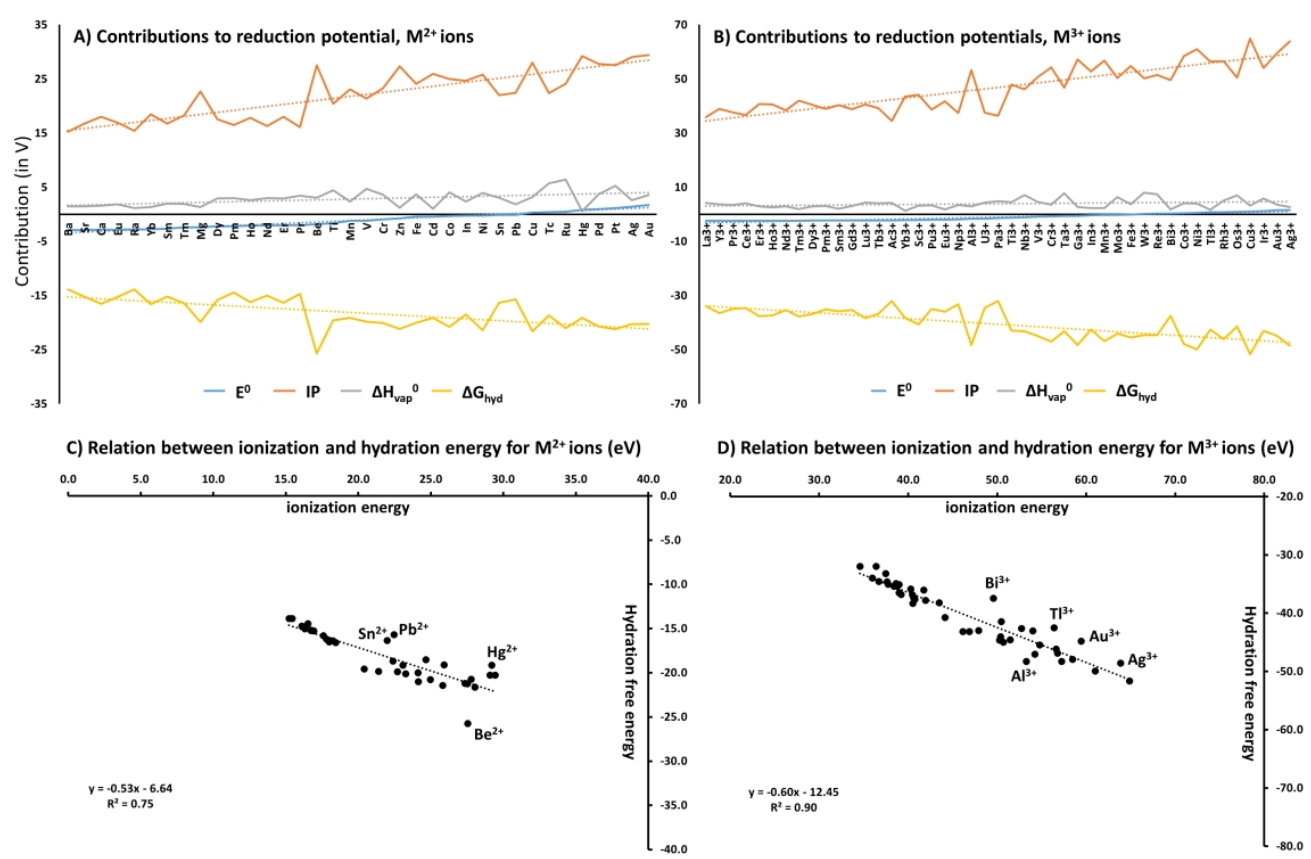

Figure 4

$321 \times 210 \mathrm{~mm}(300 \times 300$ DPI) 


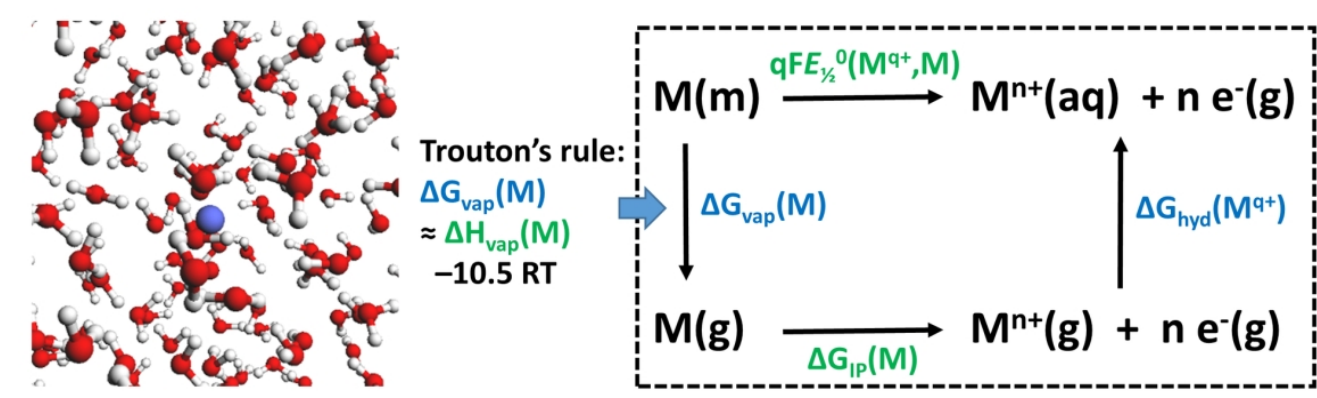

$81 \times 24 \mathrm{~mm}(600 \times 600 \mathrm{DPI})$ 